\title{
A mechanistic analysis of tropical Pacific dynamic sea level in GFDL-OM4 under OMIP-I and OMIP-II forcings
}

\author{
Chia-Wei Hsu ${ }^{1}$, Jianjun Yin ${ }^{1}$, Stephen M. Griffies ${ }^{2,3}$, and Raphael Dussin ${ }^{2}$ \\ ${ }^{1}$ University of Arizona, Department of Geoscience, 1040 E 4th St, Tucson, AZ, USA \\ ${ }^{2}$ NOAA Geophysical Fluid Dynamics Laboratory, Princeton, NJ, USA \\ ${ }^{3}$ Princeton University Atmospheric and Oceanic Sciences Program, Princeton, NJ, USA
}

Correspondence: Chia-Wei Hsu (chiaweih@ arizona.edu)

Received: 12 November 2020 - Discussion started: 30 November 2020

Revised: 20 March 2021 - Accepted: 29 March 2021 - Published: 5 May 2021

\begin{abstract}
The sea level over the tropical Pacific is a key indicator reflecting vertically integrated heat distribution over the ocean. Here, we use the Geophysical Fluid Dynamics Laboratory global ocean-sea ice model (GFDL-OM4) forced by both the Coordinated Ocean-Ice Reference Experiment (CORE) and Japanese 55-year Reanalysis (JRA-55)-based surface dataset for driving ocean-sea ice models (JRA55-do) atmospheric states (Ocean Model Intercomparison Project (OMIP) versions I and II) to evaluate the model performance and biases compared against available observations. We find persisting mean state dynamic sea level (DSL) bias along $9^{\circ} \mathrm{N}$ even with updated wind forcing in JRA55-do relative to CORE. The mean state bias is related to biases in wind stress forcing and geostrophic currents in the 4 to $9^{\circ} \mathrm{N}$ latitudinal band. The simulation forced by JRA55-do significantly reduces the bias in DSL trend over the northern tropical Pacific relative to CORE. In the CORE forcing, the anomalous westerly wind trend in the eastern tropical Pacific causes an underestimated DSL trend across the entire Pacific basin along $10^{\circ} \mathrm{N}$. The simulation forced by JRA55-do significantly reduces the bias in DSL trend over the northern tropical Pacific relative to CORE. We also identify a bias in the easterly wind trend along $20^{\circ} \mathrm{N}$ in both JRA55-do and CORE, thus motivating future improvement. In JRA55-do, an accurate Rossby wave initiated in the eastern tropical Pacific at seasonal timescale corrects a biased seasonal variability of the northern equatorial countercurrent in the CORE simulation. Both CORE and JRA55-do generate realistic DSL variation during El Niño. We find an asymmetry in the DSL pattern on two sides of the Equator is strongly related to wind stress curl that follows the sea level pressure evolution during El Niño.
\end{abstract}

\section{Introduction}

A key goal for the Coupled Model Intercomparison Project phase 6 (CMIP6), including the CMIP6 Ocean Model Intercomparison Project (OMIP), is to determine and to understand systematic model biases compared with observations, including both internal climate variability and externally forced changes (Eyring et al., 2016; Griffies et al., 2016). In this paper, we focus on model biases found in OMIP simulations of the tropical Pacific, defined as the region within the $20^{\circ} \mathrm{S}-20^{\circ} \mathrm{N}$ zonal band inside the Pacific basin. This region is characterized by some of the most significant sea level variability on interannual timescales (up to several hundreds of millimeters). The nations in this region are highly affected by such variations as well as long-term trends, thus making a systematic analysis of tropical Pacific sea level biases important both societally and scientifically.

Sea level in the tropical Pacific is dominated by the ocean heat content variability and long-term trends. Given the large size of this oceanic region, there is a high correlation between tropical Pacific sea level and global mean surface temperature at interannual and longer timescales (Trenberth, 2002; Peyser et al., 2016; Hamlington et al., 2020). Hence, an accurate simulation of the tropical Pacific sea level variability and evolution supports a mechanistic understanding of climate variability and trends using forced ocean models, as well as their prediction using coupled climate models.

Studies of the mean state and seasonal cycle of tropical Pacific sea level started well before the routine availability of satellite altimetry measurements and realistic global climate models (Wyrtki, 1974). Some studies focused on the 
sea level changes during one or two specific El Niño events due to the uniqueness and the available sea level observation from tide gauges (Cane, 1984; Busalacchi and Cane, 1985). In the current study, we use a CMIP6-OMIP ocean climate model with eddy-permitting grid spacing forced by OMIP-I and OMIP-II surface atmospheric fields. OMIP-I is forced by the Coordinated Ocean-Ice Reference Experiment (CORE) dataset of Large and Yeager (2009) and it extends over the years 1948-2007 (hereafter, CORE), whereas OMIP-II uses the Japanese 55-year Reanalysis (JRA-55)-based surface dataset for driving ocean-sea ice models (JRA55-do) of Tsujino et al. (2018), which extends over the years 19582018. Comparisons to satellite altimeter measurements support an understanding of the processes underlying tropical Pacific sea level variability and trends. Recent studies have shown improved model performance due to updated surface forcing, with particular improvements in the wind field (Taboada et al., 2018), and from refined grid spacing and improved model numerics and physics (Tsujino et al., 2020; Adcroft et al., 2019). Griffies et al. (2014) studied model performance and sea level biases for CMIP5-era ocean climate models forced by OMIP-I (CORE). The authors identified model limitations in simulating the sea level variation patterns by using the same atmospheric dataset with different ocean models. However, a detailed analysis of the mechanisms for simulation biases was lacking. Here, we take a complementary approach by performing a detailed analysis of one ocean model forced by OMIP-I (CORE) and OMIPII (JRA55-do), allowing for a detailed investigation of the causes for such model biases. We focus on tropical Pacific sea level variability and trends across different timescales, with an understanding of interannual variability in this region of particular importance for attributing observed sea level changes according to natural and anthropogenic effects.

In Sect. 2, we describe the model and experimental design for the simulations, list the observational data used to evaluate the simulations, and present the overall analysis framework. In Sect. 3, we present an analysis of the time-mean Pacific sea level patterns and the associated biases. Through the heat budget analyses, we find the mean state bias of heat advection and boundary fluxes cannot explain the sea level trend bias in simulations forced by OMIP-I and OMIP-II. An analysis is presented in Sect. 4 using decadal and longer trends to determine dominant factors causing the sea level trend bias. Besides the time-mean and long-term trend, sea level variability over seasonal and interannual timescales can also lead to significant change in the tropical Pacific. An assessment of seasonal sea level variability and interannual El Niño variability is presented in Sects. 5 and 6, respectively. The conclusion of our analysis and recommended key bias to correct in future simulations are offered in Sect. 7.

\section{Model simulations, observational data, and analysis framework}

Here, we describe the general circulation model used in this study, the experimental design for the simulations, the observational-based datasets used to evaluate the simulations, and the methodology used to conceptually frame our analysis.

\subsection{Ocean model and atmospheric forcing}

We use the Geophysical Fluid Dynamics Laboratory global ocean-sea ice model (GFDL-OM4) as documented by Adcroft et al. (2019), with OM4 having an eddy-permitting grid spacing of $0.25^{\circ}$. This relatively fine-resolution grid is especially suitable for our study of tropical Pacific sea level (defined as the region within the $20^{\circ} \mathrm{S}-20^{\circ} \mathrm{N}$ zonal band inside the Pacific basin) given that it simulates boundary currents and ocean eddies better than the more commonly used $1^{\circ}$ class of models. In addition, due to the larger Rossby radius of deformation in the tropical region compared to the midlatitudes, the eddies over the tropical region have a larger spatial scale which can be captured by the model relatively well. Furthermore, OM4 makes use of a hybrid geopotentialisopycnal vertical coordinate (Chassignet et al., 2003; Adcroft et al., 2019), which is particularly useful in maintaining a realistic tropical Pacific thermocline, whereas many $z$ coordinate models have an overly diffuse thermocline (Tseng et al., 2016; Griffies et al., 2009).

We force OM4 with the two atmospheric datasets used for OMIP versions I and II (Griffies et al., 2016; Tsujino et al., 2020). The OMIP protocol is detailed in Griffies et al. (2016) and Tsujino et al. (2020), with the use of two forcing datasets allowing us to assess robustness of simulated features and to better attribute biases. Following Tsujino et al. (2020), all simulations are spun up by running for five cycles of the respective forcing datasets, over which time the upper ocean reaches a quasi-equilibrium state. We then present our analysis for the sixth forcing cycle.

\subsection{Observationally based datasets}

Total sea level changes can be derived from satellite altimetry. The Copernicus Marine Environment Monitoring Service (CMEMS) provides a gridded sea level dataset by combining multi-mission altimeter satellite data starting from 1993 (https://resources.marine.copernicus.eu/, last access: 1 July 2019). The monthly sea surface height (SSH) anomaly from the geoid is used in this study. Following the definition of dynamic sea level (DSL) according to OMIP (Griffies et al., 2016; Gregory et al., 2019), the area-weighted global mean is removed from the observational data and model data to make them comparable.

For steric sea level anomaly and the depth-integrated density changes, we use version 4 of the Met Office Hadley 
Centre "EN" series (EN4) of datasets of global qualitycontrolled ocean temperature and salinity profile, which provides quality-controlled subsurface ocean temperature and salinity profiles based on objective analyses (Good et al., 2013) (https://www.metoffice.gov.uk/hadobs/en4/, last access: 13 August 2019). The gridded temperature and salinity profiles are used to derive density changes at all available grid cells. We also calculate the density changes solely caused by the thermal expansion (Roquet et al., 2015).

To investigate the possible bias of the wind forcing, we use the Wave and Anemometer-based Sea Surface Wind (WASwind) data (Tokinaga and Xie, 2011). The WASwind provides a global coverage of zonal and meridional wind stress based on wind observation from the International Comprehensive Ocean-Atmosphere Dataset at the monthly frequency with $4^{\circ}$ by $4^{\circ}$ grid resolution from 1950-2009. Through height correction for the anemometer-measured winds, the WASwind is not subjected to the spurious upward trend due to increases of anemometer height in the ship-based measurement. The dataset also incorporates the estimated winds from wind wave height. We find this dataset to be suitable for our analysis of the tropical Pacific, and it complements the assessment from Taboada et al. (2018), who focused on upwelling patterns in the global ocean.

\subsection{Analysis framework}

Following Gill and Niller (1973), we separate time tendencies in sea level, $\eta$, into mass and steric contributions (see Eq. 2 in Yin et al., 2010):

$$
\begin{aligned}
\frac{\partial \eta(x, y, t)}{\partial t}= & \frac{1}{g \rho_{0}} \frac{\partial\left(p_{\mathrm{b}}(x, y, t)-p_{\mathrm{a}}(x, y, t)\right)}{\partial t} \\
& -\frac{1}{\rho_{0}} \int_{-H(x, y)}^{\eta(x, y, t)} \frac{\partial \rho(x, y, z, t)}{\partial t} \mathrm{~d} z .
\end{aligned}
$$

In this equation, $g$ is the gravitational acceleration, $p_{\mathrm{a}}$ is the pressure at the ocean surface due to atmospheric mass loading (which is zero in this study when discussing DSL variation in the model), and $p_{\mathrm{b}}$ is the pressure at the ocean bottom. The first term on the right-hand side measures local sea level change due to changes in mass within a seawater column. In the second right-hand-side term, $\rho$ is the in situ seawater density, with density changes integrated over the depth of a water column (from the ocean bottom at $z=-H$ to the surface at $z=\eta$ and as normalized by the reference density $\rho_{0}=1025 \mathrm{~kg} \mathrm{~m}^{-3}$ ), yielding sea level changes from density (steric) effects. The minus sign on the steric term arises since decreases in density, as from ocean warming or freshening, lead to increases in sea level. As noted earlier, the global mean sea level time series is subtracted from all regional sea levels from observations and models to allow for direct comparisons of the resulting DSL.
Based on the 1993-2017 observational data of regional mean sea level from CMEMS and steric sea level from EN4, we find that the sea level change over this period is dominated by steric effects in the tropical Pacific (defined as the region within the $20^{\circ} \mathrm{S}-20^{\circ} \mathrm{N}$ zonal band inside the Pacific basin). The regional averaged steric signal accounts for more than $75 \%$ of the variance in the total sea level change over the eastern Pacific (180 ${ }^{\circ}$-eastern boundary) and accounts for more than $85 \%$ of the variance in the western Pacific $\left(120^{\circ} \mathrm{E}-180^{\circ}\right)$ (Fig. 1). Particularly, the steric signal within the upper $400 \mathrm{~m}$ accounts for more than $95 \%$ of the variance in the total steric signal in both the eastern and western tropical Pacific. This result shows the central role of density changes in the upper $400 \mathrm{~m}$, which mainly relates to the thermocline depth changes, in accounting for patterns of sea level variability. The residual of the sea level variance is related to the mass component (Eq. 1). These results are consistent with earlier analysis from CORE simulations documented by Griffies et al. (2014).

Density changes in the tropical Pacific are dominated by temperature changes in the upper $400 \mathrm{~m}$ (Fig. 1). For the upper $400 \mathrm{~m}$, such changes can arise from surface heat fluxes as well as lateral and vertical ocean heat transport. The surface heat flux provides a thermodynamical forcing that directly causes a local thermosteric sea level change (sea level changes due to thermal expansion) through diabatic heating. Surface wind forcing, on the other hand, induces a dynamical effect related to Ekman transport that causes light surface waters to diverge or converge, which in turn modifies sea level. Surface wind stress curl causes Sverdrup transport associated with both Ekman transport near the surface and geostrophic transport below. The internal wave propagation, like Rossby waves and Kelvin waves, at the seasonal and interannual timescales also has a large effect on the sea level variations in the tropical Pacific. All these effects can have very different contributions to sea level at different timescales and different spatial scales. In this study, we aim to characterize mechanisms that cause sea level variations and trends, and determine reasons for simulation biases.

\section{Time-mean dynamic sea level}

In this section, we focus on the time-mean DSL patterns, with the time mean computed over the years 1993-2007 that are common to both JRA55-do (OMIP-II), CORE (OMIPI), and observations (Fig. 2). This bias pattern is consistent with Griffies et al. (2014) and Tsujino et al. (2020). The only processing step difference with the previous studies is the Gaussian smoothing of the observational data. There are two reasons why smoothing is not applicable for this study. One is the larger Rossby radius of deformation in the tropical region compared to the midlatitudes. Therefore, the eddies over the tropical region have a larger spatial scale which can be captured by the model relatively well. The other reason is 

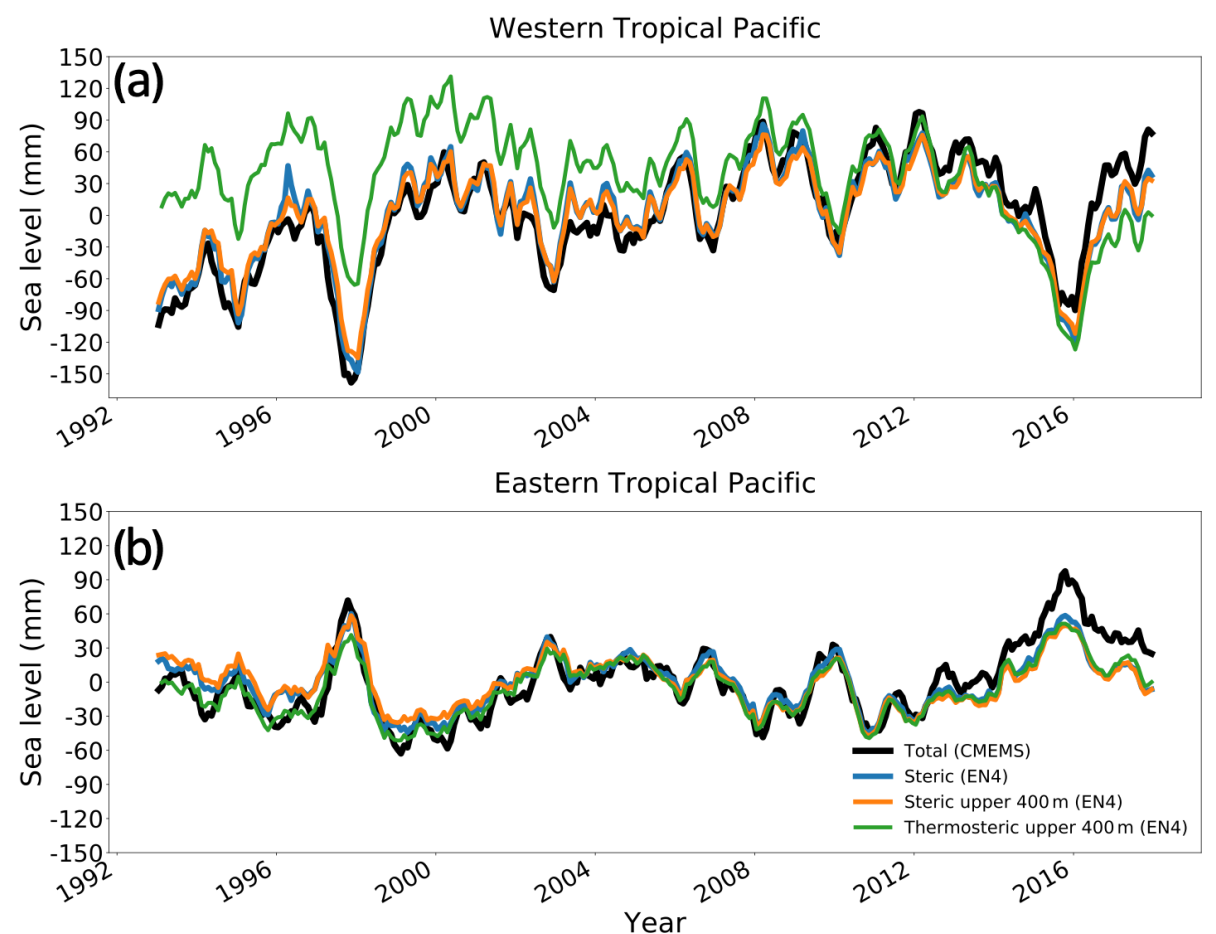

Figure 1. Time series of regional mean total sea level from CMEMS (black), steric sea level from EN4 (blue), upper $400 \mathrm{~m}$ steric sea level from EN4 (orange), and upper $400 \mathrm{~m}$ thermosteric sea level from EN4 (green) in the (a) western tropical Pacific $\left(120^{\circ} \mathrm{E}-180^{\circ}\right.$ and $\left.20^{\circ} \mathrm{S}-20^{\circ} \mathrm{N}\right)$ and $(\mathbf{b})$ eastern tropical Pacific $\left(180-60^{\circ} \mathrm{W}\right.$ and $\left.20^{\circ} \mathrm{S}-20^{\circ} \mathrm{N}\right)$.

related to the smaller-spatial-scale comparison performed in this study. Smoothing would skew and decrease the amplitude of the smaller-scale signal in the observational data. The following analyses will concentrate on the tropical Pacific region (defined as the region within the $20^{\circ} \mathrm{S}-20^{\circ} \mathrm{N}$ zonal band inside the Pacific basin).

\subsection{Role of surface wind stress}

Over the tropical Pacific, distribution of DSL can be explained well by the surface wind stress in the mean state (Fig. 3a). Especially in the Northern Hemisphere, the largescale Ekman transport toward the northwest Pacific, induced by trade winds, results in the notable DSL ridge related to the subtropical gyre. This DSL ridge creates a downgradient sea level toward the eastern basin that generates the eastward pressure gradient force that balances the Coriolis force plus the westward wind stress. To calculate the mean state bias, we calculate the time-mean DSL during the common period of 1993-2007 for JRA55-do and CORE, and subtract the CMEMS mean state from the simulations (Fig. 3b, c). Both simulations show a negative bias in most of the tropical Pacific basin except along the zonal band of $10^{\circ} \mathrm{N}$.

Because the bias shows largely zonal structures, we investigate the zonal mean DSL and wind stress in the tropical Pacific. Figure $4 \mathrm{a}$ shows that the DSL in the simulation is generally lower than the observation by about $0.02 \mathrm{~m}$ ex- cept near $10^{\circ} \mathrm{N}$. The meridional gradient of the zonal mean DSL, which is highly correlated with the narrow zonal currents in the tropical Pacific, is comparable with the observation in the Southern Hemisphere. The Northern Hemisphere, on the other hand, shows underestimated DSL gradient in two zonal bands, $9-20^{\circ} \mathrm{N}$ and $4-9^{\circ} \mathrm{N}$ due to the lack of DSL trough around $9^{\circ} \mathrm{N}$ and DSL ridge at $4^{\circ} \mathrm{N}$. Between 9- $20^{\circ} \mathrm{N}$, the downgradient DSL toward the Equator is associated with the strength of North Equatorial Current (NEC). Between $4-9^{\circ} \mathrm{N}$, the upgradient DSL toward the Equator is associated with the strength of North Equatorial Countercurrent (NECC). Therefore, the smaller or missing DSL gradient in both simulations could lead to underestimated NEC and NECC.

For the mean state of surface wind forcing, we compare the wind stress curl and the associated circulation strength (defined as the maximum value of the Sverdrup stream function along each latitude) between the forcing dataset and the observation from WASwind. The Sverdrup stream function is defined as

$\Psi=-\int_{\mathrm{EB}}^{x} \frac{\nabla \times \boldsymbol{\tau}}{\beta \rho_{0}} \mathrm{~d} x$,

where EB indicates the eastern boundaries of the tropical Pacific at each latitude, $\tau$ is the wind stress vector, $\beta=\mathrm{d} f / \mathrm{d} y$ is the meridional derivative of the Coriolis parameter, $f$, and 
(a)
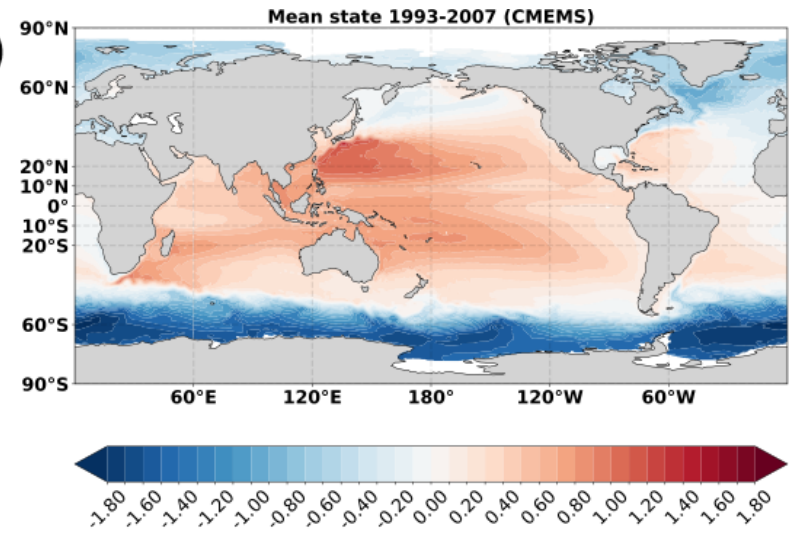

Dynamic sea level $(\mathrm{m})$

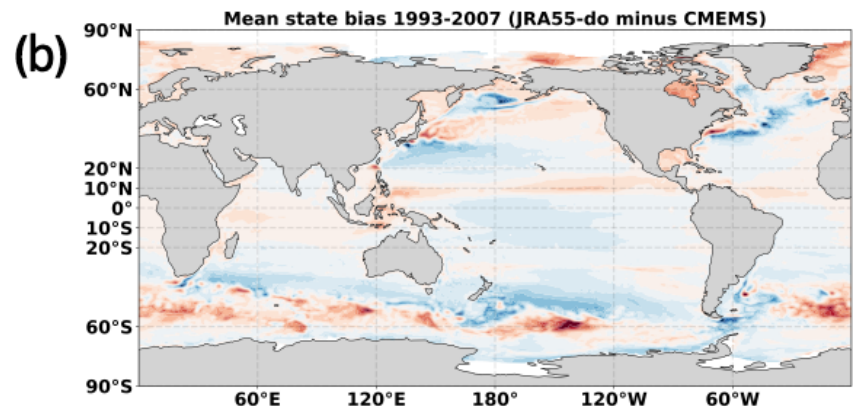

(c)
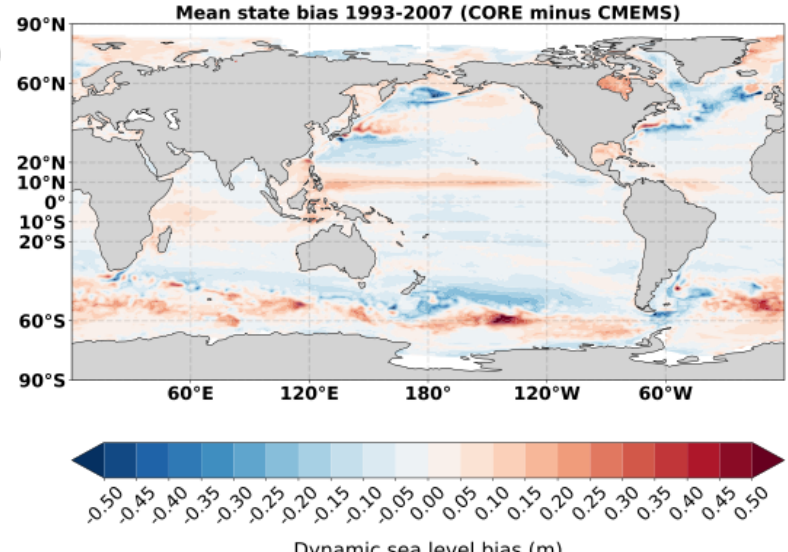

Dynamic sea level bias $(\mathrm{m})$

Figure 2. (a) The shaded color shows the DSL time mean (19932007) from satellite altimeter measurements (CMEMS). The shaded color shows DSL bias in (b) the JRA55-do-forced simulation and (c) the CORE-forced simulation during the 1993-2007 period.

$\rho_{0}=1025 \mathrm{~kg} \mathrm{~m}^{-3}$ is the reference density. Figure $4 \mathrm{~b}-\mathrm{d}$ show the zonal mean of zonal wind stress $\left(\tau_{x}\right)$, wind stress curl $(\nabla \times \tau)$ bias, and circulation strength bias, respectively. The wind stress curl bias is dominated by the zonal wind shear bias (Fig. 4c). Although the zonal wind stress is generally similar between observations and simulations (Fig. 4b), the wind stress curl bias is sensitive to even small differences. The wind stress curl bias shows a large positive bias at around $4^{\circ} \mathrm{N}$ and a negative bias at around $9^{\circ} \mathrm{N}$ (Fig. 4c). The JRA55- do and CORE do not exactly capture some subtle features in the observation, such as the sharp zonal wind shear across the Intertropical Convergence Zone (ITCZ) and the comparatively uniform zonal wind stress in $0-5^{\circ} \mathrm{N}$ latitudes. This difference creates a negative bias in Sverdrup stream function (counterclockwise circulation bias) at $4^{\circ} \mathrm{N}$ and positive bias (clockwise circulation bias) at $9^{\circ} \mathrm{N}$ (Fig. 4d). Since the geostrophic flow components dominate the Sverdrup stream function, the counterclockwise circulation bias represents a negative DSL bias at the circulation center, and the clockwise circulation bias represents a positive DSL bias at the circulation center. These opposite DSL biases induced by the wind stress flatten the DSL ridge and trough in this region, thus decreasing the sea level gradient in both zonal bands. This analysis highlights the importance of an accurate representation of the zonal wind stress shear for simulating the DSL trough and the associated zonal currents in the $4-9^{\circ} \mathrm{N}$ band of the tropical Pacific.

\subsection{The role of zonal currents in the ocean heat budget}

To analyze the impact of zonal currents on heat, we consider two boxes within the tropical Pacific and assess the mean heat advection and volume transport from individual currents. For this purpose, we define a western box (Wbox, with boundaries $120^{\circ} \mathrm{E}-180^{\circ} ; 20^{\circ} \mathrm{S}-20^{\circ} \mathrm{N} ; 0-400 \mathrm{~m}$ ) and an eastern box (Ebox, with boundaries $180^{\circ}$-eastern boundary; $20^{\circ} \mathrm{S}-20^{\circ} \mathrm{N} ; 0-400 \mathrm{~m}$ ), as shown in Fig. 5, and express the heat budget as

$$
\begin{aligned}
\iiint_{V} \frac{\partial Q}{\partial t} \mathrm{~d} V= & F_{\mathrm{srf}}-\rho_{0} C_{p} \iint_{S}(\boldsymbol{u} \cdot \hat{\boldsymbol{n}})\left(T-T_{\mathrm{m}}\right) \mathrm{d} S \\
& +<\text { residual }>.
\end{aligned}
$$

In this equation, $\iiint_{V} \frac{\partial Q}{\partial t} \mathrm{~d} V$ is the heat content changes in a box, which is related to the thermosteric sea level changes, and $F_{\text {srf }}$ is the area integrated net surface heat flux. $T_{\mathrm{m}}$ represents the volume mean temperature inside a box. For Wbox, $T_{\mathrm{m}}=T_{\mathrm{mw}}$ and for Ebox, $T_{\mathrm{m}}=T_{\mathrm{me}}$. We calculate the heat advective transport term following the analysis of Lee et al. (2004) and Ray et al. (2018). The residual term accounts for transport from small-scale processes including vertical mixing, subgrid-scale processes; these processes are not of concern here and are small compared to the role of currents.

The heat advection across the $180^{\circ}$ transect dominates the heat content changes (thermosteric sea level changes, Fig. 1) in the Wbox (Fig. 6), whereas a compensation between surface heat flux and heat advection across the $180^{\circ}$ transect is important in the Ebox. For the Ebox, the compensation between $180^{\circ}$ heat advection and surface heat flux shows the eastern tropical Pacific as an important region for heat to enter the ocean and then to participate in the global energy cycle, which is consistent with the finding of diabatic heating at the surface controlling the heat movement over the ocean (Holmes et al., 2019). Despite the large net surface heat flux 

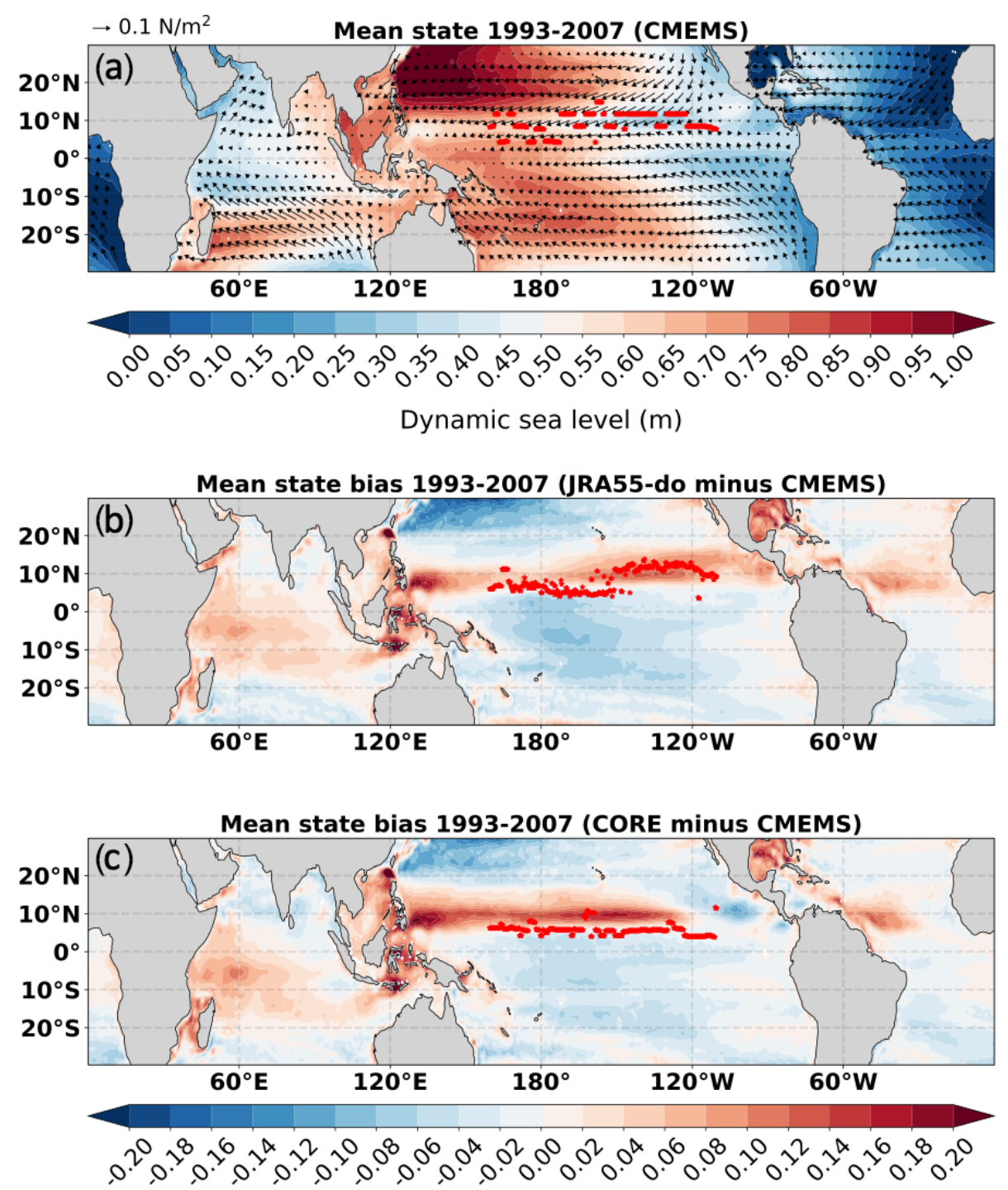

Dynamic sea level bias $(\mathrm{m})$

Figure 3. (a) The shaded color shows the DSL time mean (1993-2007) from satellite altimeter measurements (CMEMS) and the vector field shows the wind stress time mean from WASwind (see the $0.1 \mathrm{~N} \mathrm{~m}^{-2}$ vector in the upper left for scale). The shaded color shows DSL bias in (b) the JRA55-do-forced simulation and (c) the CORE-forced simulation during the 1993-2007 period. The red stars indicate the Intertropical Convergence Zone (ITCZ) location as determined by the maximum wind convergence at each longitude over the tropical Pacific.

in the Ebox, the heat is not stored in the eastern tropical $\mathrm{Pa}$ cific but flushed to the western tropical Pacific. We find that, with larger net heat flux over the Ebox, the heat advection across the $180^{\circ}$ transect is also larger in CORE than JRA55do (see the detailed comparison in the next paragraph). For the Wbox, the main heat loss occurs at the $120^{\circ} \mathrm{E}$ transect, which advects the heat out with the magnitude a little less than half of the heat coming from the eastern tropical Pacific. Heat loss also occurs across the other three boundaries of the Wbox but is considerably smaller than across the $120^{\circ} \mathrm{E}$ transect. Besides some small differences in surface heat flux and the heat advection at the $180^{\circ}$ transect, we do not see signif- icant differences in the mean state heat budget between the simulations forced by CORE and JRA55-do.

Due to the importance of zonal heat transport between the two boxes, we look into the dominant currents and their relative contributions to the $180^{\circ}$ transect (Fig. 6b, c). We define the current based on the time mean of the zonal velocity (Fig. 6d). The South Equatorial Current (SEC) is defined by the westward mean zonal velocity within $20^{\circ} \mathrm{S}$ to $5^{\circ} \mathrm{N}$ zonal band and above $400 \mathrm{~m}$. Both CORE- and JRA55-do-forced simulations show that the SEC makes the largest contribution to the heat content changes in Wbox and Ebox with similar magnitude. The NEC, which is defined by the westward 
(a)

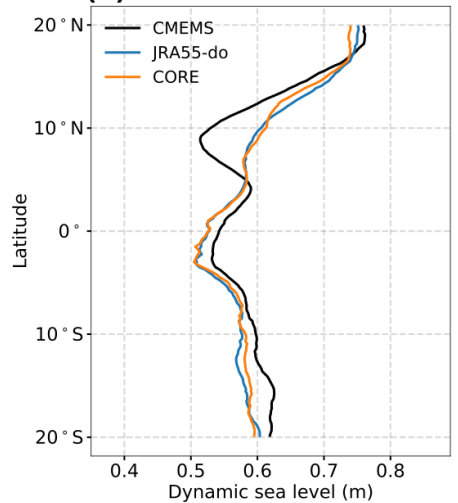

(b)

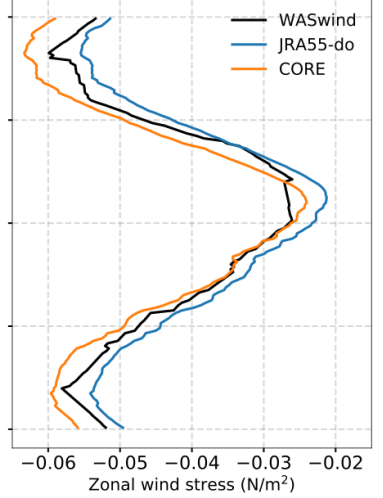

(c)

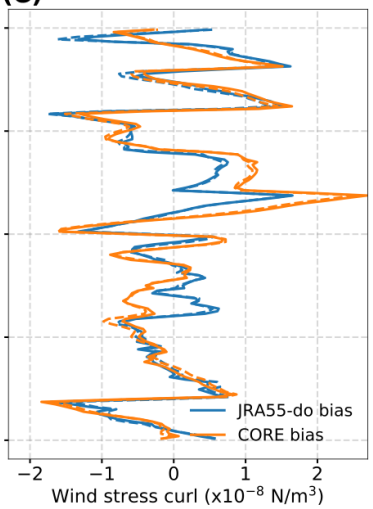

(d)

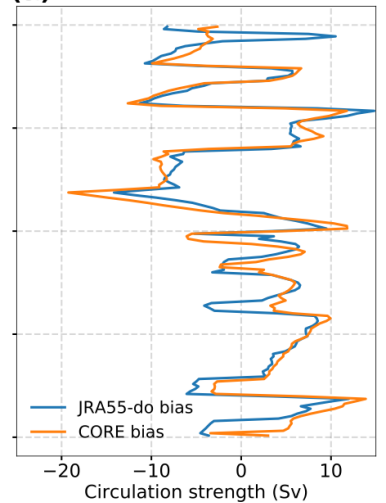

Figure 4. Figures show the zonal mean profile of (a) DSL from CMEMS and OMIP simulations (JRA55-do and CORE), (b) zonal wind stress from WASwind and OMIP forcing data (JRA55-do and CORE), (c) wind stress curl bias (solid) and zonal-wind-induced wind stress curl bias (dashed) for the simulations, and (d) the bias of circulation strength defined as the maximum value of the Sverdrup stream function for the simulations along each latitude over the tropical Pacific.

Western Box

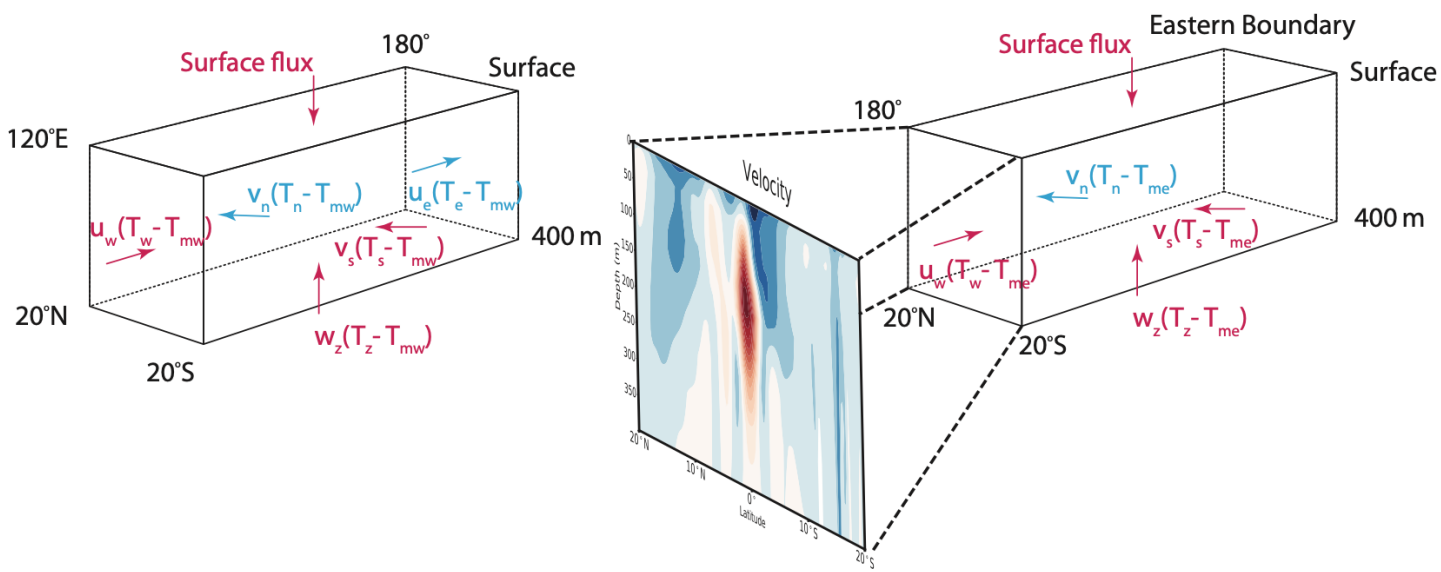

Figure 5. The two-box regions for the heat budget analysis, with the western box (Wbox) and the eastern box (Ebox) shown over the tropical Pacific. The western box is from $120^{\circ} \mathrm{E}-180^{\circ}, 20^{\circ} \mathrm{S}-20^{\circ} \mathrm{N}$, and $0-400 \mathrm{~m}$, and the eastern box is from $180^{\circ}-$ eastern boundary, $20^{\circ} \mathrm{S}-20^{\circ} \mathrm{N}$, and $0-400 \mathrm{~m}$. All variables are a function of space and time. $T$ is potential temperature; $u, v$, and $w$ are the velocity components in the $\hat{\boldsymbol{x}}$, $\hat{\boldsymbol{y}}$, and $\hat{z}$ directions, respectively. Subscripts w, e, s, n, and $z$ represent the western, eastern, southern, northern, and bottom boundaries of the boxes, respectively. $T_{\mathrm{mw}}$ and $T_{\mathrm{me}}$ represent the volume mean temperature in the Wbox and the Ebox, respectively. The velocity field transect across $180^{\circ}$ between Wbox and Ebox is shown by the shaded field, where a positive value represents eastward flow. Detailed defined current systems based on the velocity field are shown in Fig. 6d.

mean zonal velocity within $5-20^{\circ} \mathrm{N}$ zonal band and above $400 \mathrm{~m}$, shows the second-largest contribution. The heat advection of NEC in CORE is around $50 \%$ larger than JRA55do. This difference in heat advection is a result of the larger mean zonal current speed in the CORE-forced simulation (Fig. 6c). Interestingly, we also see a higher energy input in the northern part of Ebox (Fig. 7) in CORE, which reiterates the concept that the energy input in the Ebox is always flushed toward the Wbox in the simulations. The Equatorial Undercurrent (EUC), which is defined by the eastward mean zonal velocity within $2.5^{\circ} \mathrm{S}-2.5^{\circ} \mathrm{N}$ zonal band, largely com- pensates for the westward heat advection by the SEC and the NEC in both JRA55-do and CORE forcing. Both the NECC, defined by the eastward mean zonal velocity within the 2.5 to $10^{\circ} \mathrm{N}$ zonal band, and South Equatorial Countercurrent (SECC), defined by the eastward mean zonal velocity within the 2.5 to $10^{\circ} \mathrm{S}$ zonal band, show little contribution to heat content change for both boxes.

To check for current biases, we compare the speed and volume transport of each current system in JRA55-do and CORE with the available observational data (Table 1). The EUC is well represented, with a simulated maximum value 
(a)

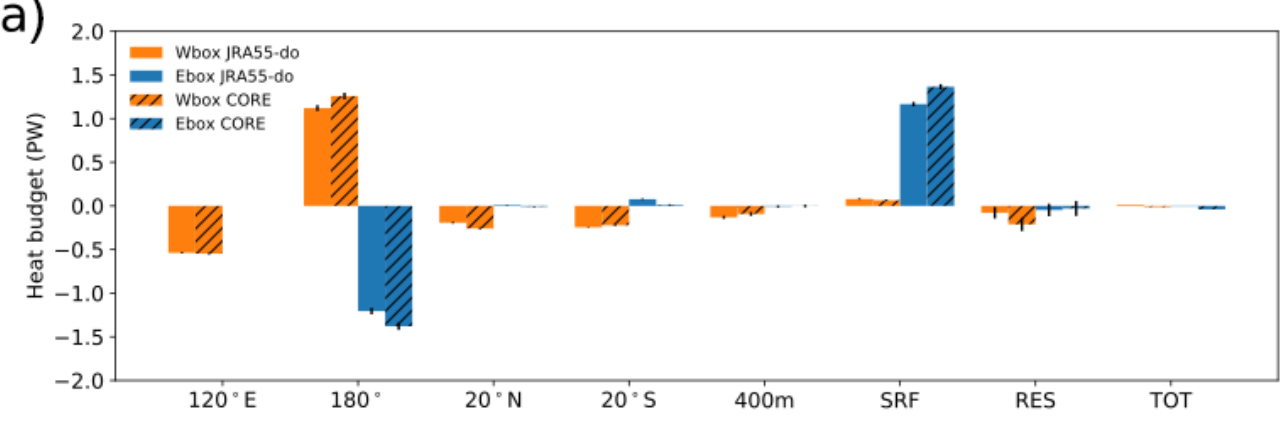

(b)

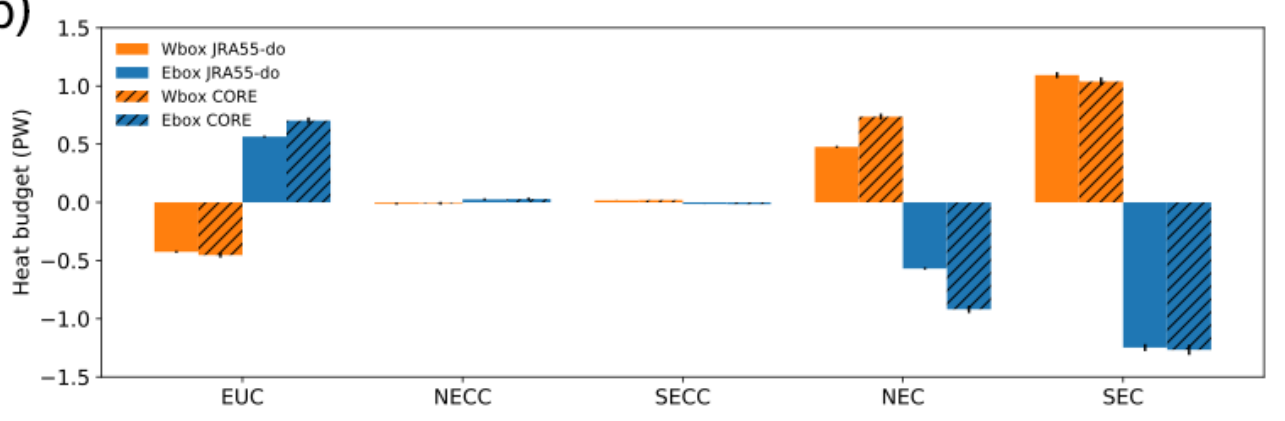

(c)

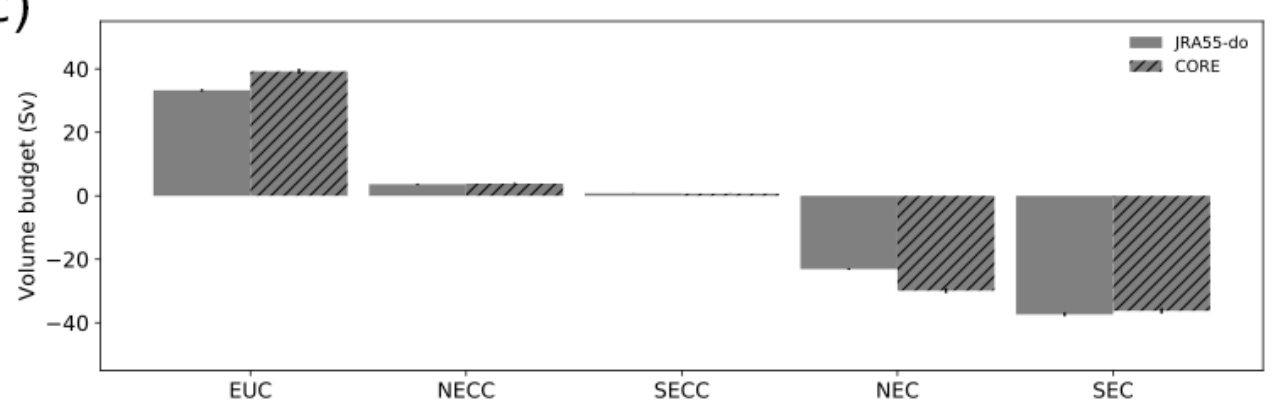

(d)

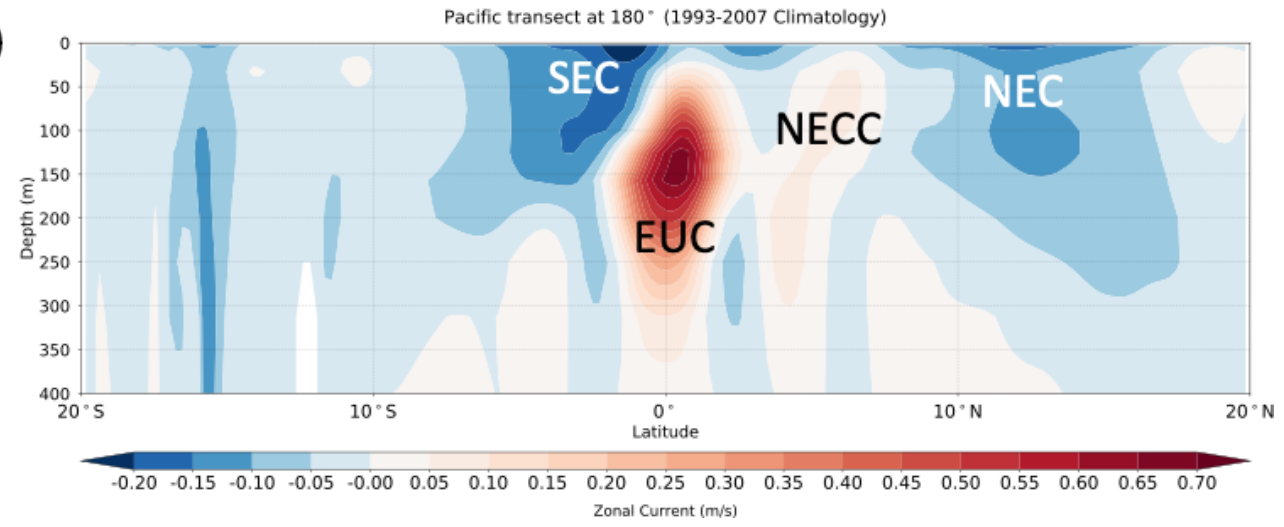

Figure 6. The 1993-2007 time-mean (a) heat contribution from advection across different transects $\left(120^{\circ} \mathrm{E}, 180^{\circ}, 20^{\circ} \mathrm{S}, 20^{\circ} \mathrm{N}, 400 \mathrm{~m}\right)$, surface flux (SRF), and the residual processes calculated as the difference between the total heat content tendency in the box (TOT) and the sum of SRF and heat advection from all boundaries. The filled yellow and blue bars represent Wbox and Ebox, respectively. The JRA55-do(no stripe) and CORE-forced (with stripes) simulations are shown side by side for comparison. The mean state of the individual current system contributing to the (b) heat budget through heat advection and (c) the associated volume transport across $180^{\circ}$ transect are shown. The error bar shows the $99 \%$ confidence interval of the mean value. Panel (d) shows the mean zonal velocity from the JRA55-do simulation at $180^{\circ}$ transect in the tropical Pacific where positive means eastward velocity. The text shows each defined current system. 

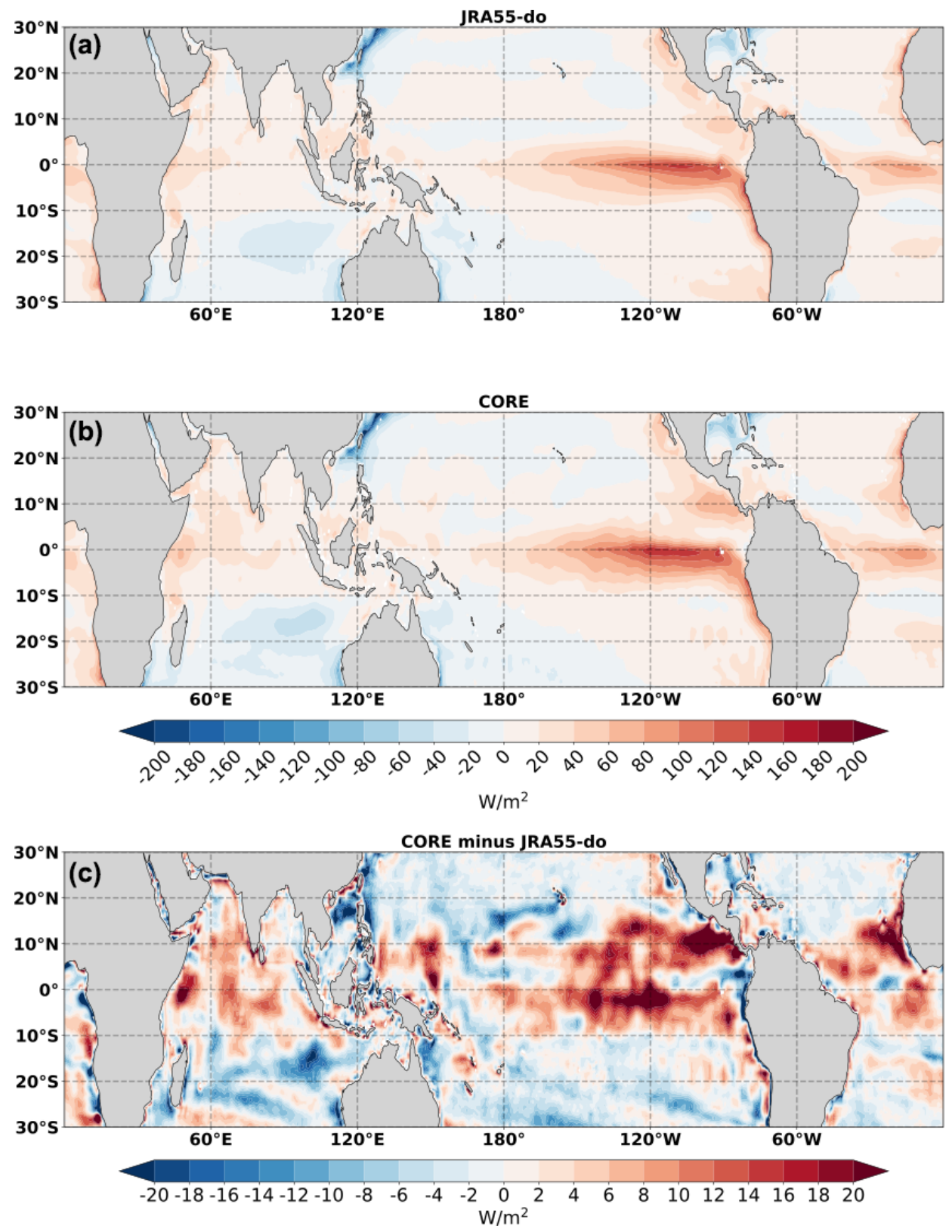

Figure 7. The 1993-2007 time-mean net surface heat flux in JRA55-do (a), CORE (b), and CORE minus JRA55-do (c). Positive value indicates an energy flux into the ocean. Note the different scales of the two color bars.

Table 1. Comparison between observation and JRA55-do/CORE simulations for various tropical Pacific currents.

\begin{tabular}{lllll}
\hline Currents & Characteristics & JRA55-do & CORE & Observations \\
\hline EUC $\left(2.5^{\circ} \mathrm{S}-2.5^{\circ} \mathrm{N}\right)$ & max speed & $1.2 \mathrm{~m} \mathrm{~s}^{-1}$ & $1.2 \mathrm{~m} \mathrm{~s}^{-1}$ & $1.1 \mathrm{~m} \mathrm{~s}^{-1}$ (Johnson et al., 2002) \\
& max speed depth & $100 \mathrm{~m}$ & $100 \mathrm{~m}$ & $86 \mathrm{~m}^{\text {(Johnson et al., 2002) }}$ \\
& max speed longitude & $138^{\circ} \mathrm{W}$ & $129^{\circ} \mathrm{W}$ & $130^{\circ} \mathrm{W}$ (Johnson et al., 2002) \\
& meridional extent at $180^{\circ}$ & $2^{\circ} \mathrm{S}-2^{\circ} \mathrm{N}$ & $2^{\circ} \mathrm{S}-3^{\circ} \mathrm{N}$ & $2^{\circ} \mathrm{S}-2^{\circ} \mathrm{N}$ (Johnson et al., 2002) \\
SEC $\left(20^{\circ} \mathrm{S}-2.5^{\circ} \mathrm{N}\right)$ & max speed at $180^{\circ}$ & $0.2 \mathrm{~m} \mathrm{~s}^{-1}$ & $0.2 \mathrm{~m} \mathrm{~s}^{-1}$ & $0.2 \mathrm{~m} \mathrm{~s}^{-1}$ (Johnson et al., 2002) \\
NECC $\left(10^{\circ} \mathrm{S}-2.5^{\circ} \mathrm{S}\right)$ & max speed at $180^{\circ}$ & $0.1 \mathrm{~m} \mathrm{~s}^{-1}$ & $0.1 \mathrm{~m} \mathrm{~s}$ & $0.4 \mathrm{~m} \mathrm{~s}^{-1}$ (Johnson et al., 2002) \\
NEC $\left(2.5-20^{\circ} \mathrm{N}\right)$ & volume transport at $180^{\circ}$ & $23 \mathrm{~Sv}$ & $29 \mathrm{~Sv}$ & $40 \mathrm{~Sv}$ (Zhang et al., 2017) \\
\hline
\end{tabular}


of $1.2 \mathrm{~m} \mathrm{~s}^{-1}$ at approximately $100 \mathrm{~m}$ depth at $138^{\circ} \mathrm{W}$ in JRA55-do and $1.2 \mathrm{~m} \mathrm{~s}^{-1}$ at approximately $100 \mathrm{~m}$ depth at $129^{\circ} \mathrm{W}$ in CORE along the Equator, which compares to an observed value of $1.1 \mathrm{~m} \mathrm{~s}^{-1}$ at approximately $86 \mathrm{~m}$ at $130^{\circ} \mathrm{W}$ from Johnson et al. (2002). The meridional extension of the EUC is also well simulated compared to the observed current confined between $2^{\circ} \mathrm{S}$ and $2^{\circ} \mathrm{N}$ at $180^{\circ}$ in JRA55-do and $2^{\circ} \mathrm{S}$ and $3^{\circ} \mathrm{N}$ in CORE which skews more toward the Northern Hemisphere (Johnson et al., 2002). The SEC at $180^{\circ}$ shows good agreement in strength with the observed maximum value of $0.2 \mathrm{~m} \mathrm{~s}^{-1}$ for both JRA55-do and CORE (Johnson et al., 2002). Due to the underestimated DSL gradient in the Northern Hemisphere and the missing DSL trough, weaker NEC and NECC in JRA55-do and CORE are expected. The observed NECC strength is $0.4 \mathrm{~m} \mathrm{~s}^{-1}$, while the simulations show a much weaker value of $0.1 \mathrm{~m} \mathrm{~s}^{-1}$. The weak NECC bias exists in the JRA55-do-forced simulation as well as the CORE-forced simulation, with Tseng et al. (2016) attributing the CORE simulation biases to an inaccurate wind stress representation. Unfortunately, the improved surface wind forcing from JRA55-do did not resolve the underestimation of the NECC. The NEC is also underestimated due to the flattening of the DSL trough for both simulations. Namely, the NEC transport in the JRA55-do-forced simulation is 23 and $29 \mathrm{~Sv}$ in CORE, whereas the Argo-derived value is near $40 \mathrm{~Sv}$ (Zhang et al., 2017).

When we compare NECC and NEC in both model simulations, the heat advection between Wbox and Ebox from the NEC is significantly larger than that from the NECC. Therefore, the Northern Hemisphere heat content changes in Ebox and Wbox are dominated by the NEC. Heat content changes are related to thermosteric sea level changes, so that a stronger NEC heat advection can explain the stronger eastwest gradient in the DSL trend found in the Northern Hemisphere in CORE relative to JRA55-do (Fig. 8b, c). However, the weak NEC bias and difference between CORE and JRA55-do cannot explain the consistent underestimation of the DSL trend along the $10^{\circ} \mathrm{N}-20^{\circ} \mathrm{N}$ zonal band in both the CORE- and JRA55-do-forced simulations (Fig. 9a, b).

\section{Dynamic sea level trend}

Over the 1993-2012 period, satellite altimetry has shown a significant sea level rise which is associated with the warming trend in the western tropical Pacific (Fig. 8). The trend has been extensively studied due to its significant asymmetric zonal pattern over the tropical Pacific which is related to global warming rates and decadal variability (Peyser et al., 2016; Merrifield, 2011; Bromirski et al., 2011; Zhang and Church, 2012; Hamlington et al., 2014). Though the asymmetry in the DSL trend is significant in the observations, ocean model simulations forced by CORE have failed to represent this DSL trend pattern (Griffies et al., 2014). Our model simulations consistently underestimate the DSL trend along the $10-20^{\circ} \mathrm{N}$ zonal band even with the updated surface forcing from JRA55-do (Fig. 9). The reason for this simulated DSL trend bias has not been discussed in the literature.

Figure $9 \mathrm{a}, \mathrm{b}$ show the DSL trend and bias by subtracting the CMEMS DSL trend from the simulations forced by CORE and JRA55-do. The trend bias, though still present, is significantly reduced with JRA55-do. The zonal mean DSL trend between $10-20^{\circ} \mathrm{N}$ is underestimated by $1 \mathrm{~mm} \mathrm{yr}^{-1}$ on average in JRA55-do and much larger bias of $4 \mathrm{~mm} \mathrm{yr}^{-1}$ underestimation with CORE (Fig. 10a). By subtracting the JRA55-do simulation from the CORE simulation, we also find that the differences between CORE and JRA55-do are similar to those of the CORE bias (CORE minus CMEMS) (Fig. 9c). This result shows the bias reduction in JRA55-do is significant and has a trend better matching the CMEMS DSL trend.

Furthermore, we extend the trend calculation to 50 years (1958-2007) and calculate the trend difference between the JRA55-do and CORE simulations (Fig. 9d). The bandstructured DSL trend difference persists for the longer time period (1958-2007) (Fig. 9d). The zonal mean of DSL trend in the tropical Pacific also shows the underestimated DSL trend between $5-20^{\circ} \mathrm{N}$ (Fig. 10b).

\subsection{Ekman layer response}

To help reveal mechanisms for the underestimation of the DSL trend, we investigate the wind stress forcing in CORE and JRA55-do and compare it with the WASwind observational product. We calculate the wind stress trend bias by subtracting the WASwind wind stress trend from CORE and JRA55-do. During 1993-2007, there is no statistically significant trend bias in wind stress that can help explain the DSL trend bias. For the trend significance test, the null hypothesis in the statistical test is zero long-term trend with an effective degree of freedom considering the autocorrelation of the time series. The large variability of wind stress and the small number of samples during this period result in an inconclusive statistical test. However, with the increased number of samples during a longer period (1958-2007), a statistically significant zonal wind bias in JRA55-do and CORE can be found (Fig. 11).

The most obvious bias is the excessive westerly wind trend in CORE and JRA55-do than WASwind located at the central and eastern Pacific, with the trend bias particularly large in CORE (Fig. 11c). A westerly trend in CORE extending from $10^{\circ} \mathrm{S}$ to $15^{\circ} \mathrm{N}$ can also be seen in the zonal average over the tropical Pacific (Fig. 12). The westerly trend is significantly reduced in the JRA55-do. On top of the westerly trend bias, there is an easterly trend bias in the $15-25^{\circ} \mathrm{N}$ zonal band for both JRA55-do and CORE (Fig. 11b, c). JRA55-do has an easterly trend bias only west of $150^{\circ} \mathrm{W}$, while CORE extends across the entire Pacific basin. The existence of both the westerly and easterly trend biases in CORE generates a strong positive wind stress curl trend in the $8-20^{\circ} \mathrm{N}$ zonal 

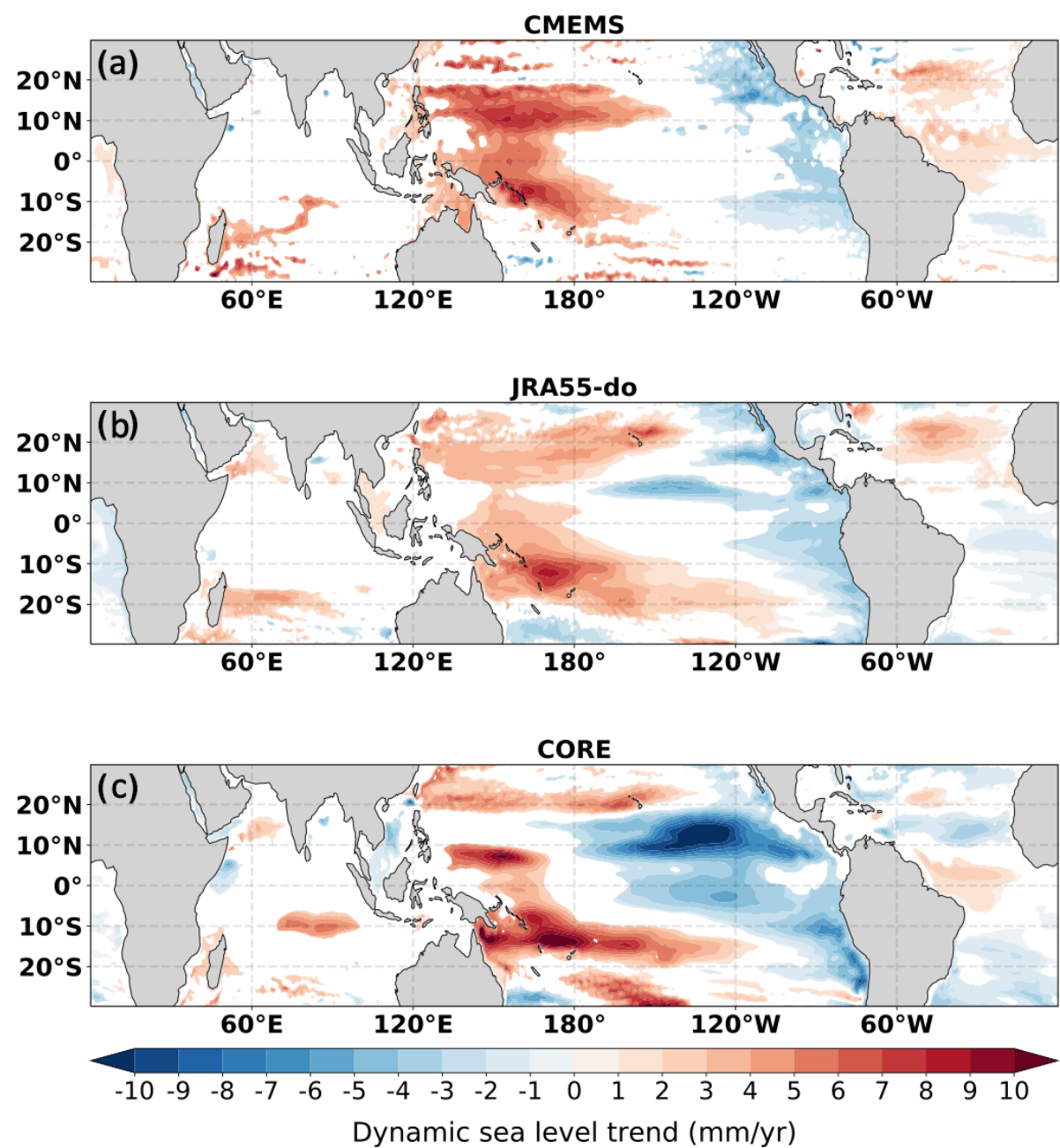

Figure 8. The linear DSL trend during the 1993-2007 period derived from (a) satellite altimeter observation (CMEMS), (b) the JRA55do-forced simulation, and (c) the CORE-forced simulation. The shaded color shows the trend that is statistically significant with $99 \%$ confidence.

band (Fig. 12b). The JRA55-do simulation also has a positive wind stress curl trend bias in the same zonal band but is roughly 3 times smaller than the CORE simulation (Fig. 12). The smaller wind stress curl trend bias with JRA55-do is mainly due to the missing westerly trend bias in the $10^{\circ} \mathrm{S}$ to $10^{\circ} \mathrm{N}$ region.

The westerly trend bias in CORE forcing data is a result of the multiplicative factor $\left(R_{S}\right)$ applied to the vector winds in the reanalysis data by Large and Yeager (2009). The multiplicative factor is determined by the 5-year mean (20002004) ratio between reanalysis data and observational data. Since the factor is designed to make the mean state of wind amplitude in reanalysis data better fit the observation, applying the same factor to the entire time series could result in biases across different timescales. In this case, the factor designed to correct the mean state causes an overestimation of the trend in the westerly wind in the eastern tropical Pacific where the factor has the highest value in the tropical Pacific (see Fig. 2a in Large and Yeager, 2009). The modified multiplicative factor that is actually used as an offsetting factor to correct JRA-55 wind in Tsujino et al. (2018) has a better adjustment without introducing the westerly trend bias. On the other hand, the easterly bias in the $15-25^{\circ} \mathrm{N}$ zonal band exists in both the JRA55-do and CORE forcing data.

We conclude from this analysis that the positive wind stress curl trend bias west of $150^{\circ} \mathrm{W}$, found in both CORE and JRA55-do, is mainly due to the easterly wind stress trend bias. Additionally, the positive wind stress curl trend bias east of $150^{\circ} \mathrm{W}$ in the CORE forcing is due to the combined effect of easterly and westerly trend biases. The positive wind stress curl trend bias in the zonal band creates an artificial Ekman suction that causes the DSL trend in the simulations to be biased low. 

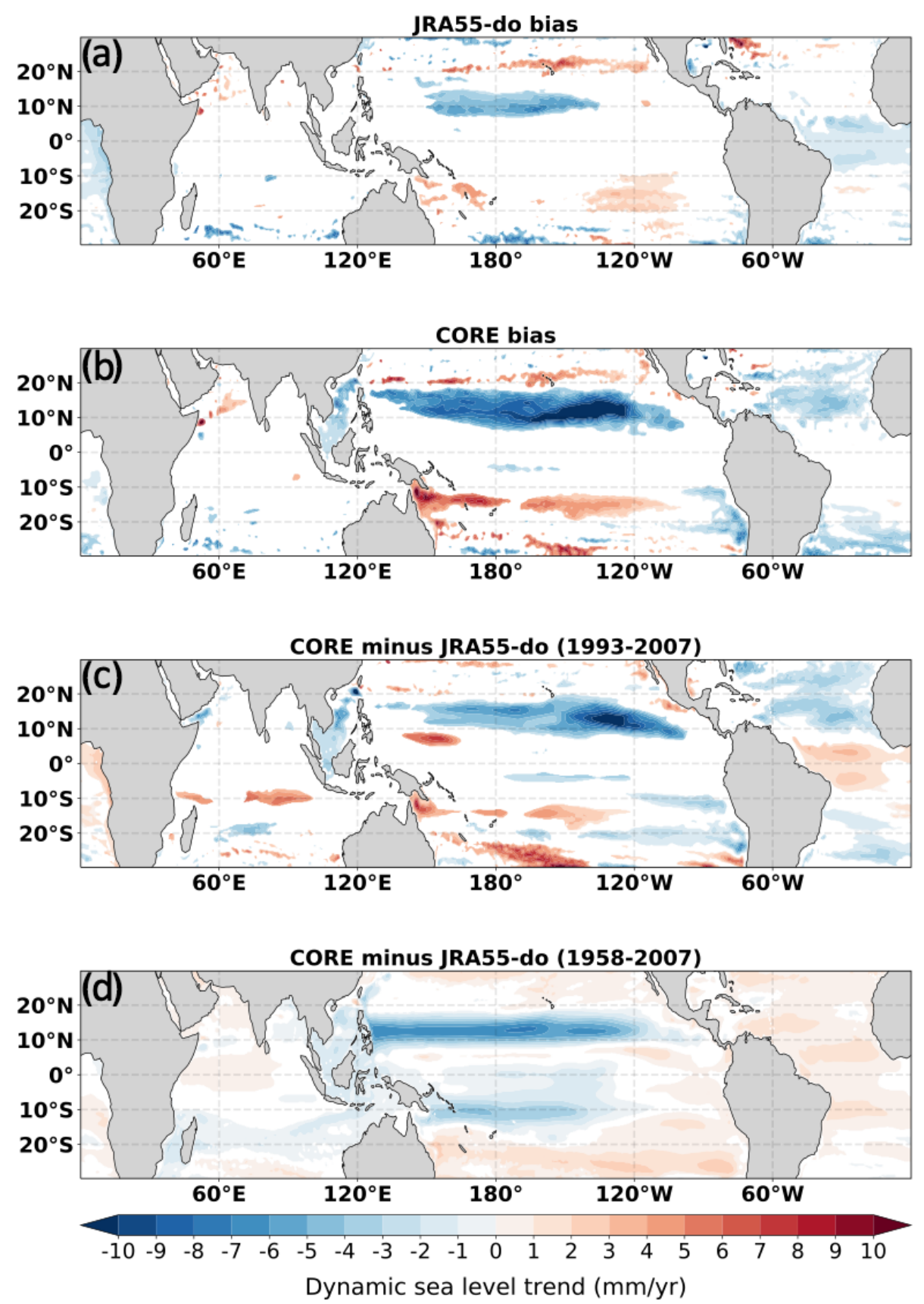

Figure 9. The DSL trend bias (CMEMS-derived DSL subtracted from the simulations) during the 1993-2007 period common to CORE and JRA55-do. Panel (a) shows the JRA55-do-forced simulation. Panel (b) shows the CORE-forced simulation. DSL trend difference is determined by subtracting JRA55-do from CORE during 1993-2007 in panel (c) and during 1958-2007 in panel (d). The shaded colors show the trend biases or differences that are statistically significant with $99 \%$ confidence.

\subsection{Barotropic response}

We now examine how the barotropic geostrophic response affects the DSL trend. From the trend bias in the Sverdrup stream function, we can see how the geostrophic flow trend bias can cause the DSL trend bias. The Sverdrup stream function $(\Psi)$ is calculated following Eq. (2). The CORE simula- tion shows a negative stream function trend bias in the 10$20^{\circ} \mathrm{N}$ zonal band, whereas the JRA55-do trend bias is relatively small (Fig. 13a, b). The negative trend bias which corresponds to a trend of counterclockwise geostrophic current is related to the negative DSL trend bias across the Pacific basin. 

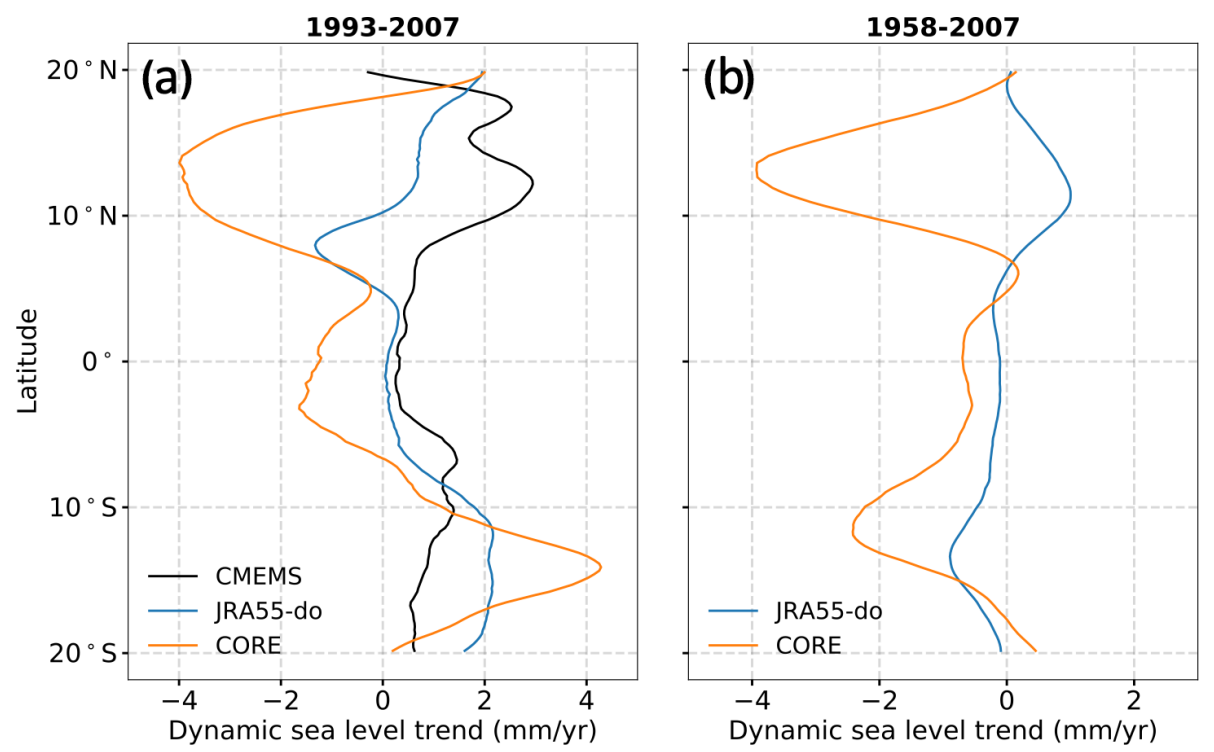

Figure 10. The zonal mean DSL trend from observations and the JRA55-do and CORE simulations during (a) 1993-2007 and simulations during (b) 1958-2007 over the tropical Pacific basin.

To further investigate the dominant causes, we perform the same Sverdrup stream function calculation starting from the eastern boundary. However, in this calculation, we stop at $150^{\circ} \mathrm{W}$, where the largest westerly wind trend bias is located, and keep the remaining basin as zeros until we reach the western boundary (Fig. 13c, d). This calculation helps to identify the contribution from the westerly trend bias in the eastern tropical Pacific. In particular, it reveals the importance of the westerly trend bias in the eastern tropical Pacific in driving the large-scale counterclockwise circulation trend bias, while the easterly wind bias along the $10-20^{\circ} \mathrm{N}$ latitude band west of $150^{\circ} \mathrm{W}$ strengthens the circulation trend bias in the CORE simulation. The Southern Hemisphere also shows the same negative DSL trend bias that can be explained by the same Ekman suction and the large-scale Sverdrup balance during 1958-2007. This analysis shows the significant effect of zonal wind stress trend biases near the Equator on the off-equatorial DSL trend biases from geostrophic balance and Ekman suction.

The large interannual to decadal variability in DSL can affect the trend and trend bias estimates over a shorter period (Bromirski et al., 2011; Zhang and Church, 2012; Hamlington et al., 2014). Based on the improved forcing from JRA55do, we calculate the DSL trend during 1993-2017 and compared with the available observational data. Despite the reduced trend bias compared to 1993-2007, Fig. 14 still shows the trend bias in the $10-20^{\circ} \mathrm{N}$ zonal band, which also shows the existence of the DSL trend bias is not due solely to interannual variability over a short time period.

The above analyses mainly focus on the tropical Pacific. To give a quantitative comparison, we also analyze the zonal mean bias across three major basins to demonstrate the sig- nificance of tropical Pacific sea level bias (Fig. 15). Pacific trend bias over the tropics in CORE is the largest across all three major basins. JRA55-do significantly reduces the bias over the tropical Pacific but has a negative bias in the extratropical region and other basins in both the Northern Hemisphere and Southern Hemisphere.

\section{Dynamic sea level seasonal variability}

Seasonal variability of DSL in the tropical Pacific is significant, especially over the Northern Hemisphere between 2 and $10^{\circ} \mathrm{N}$. For the December, January, and February (DJF) mean, we can find a clear zonal dipole structure between the western and eastern Pacific in the 2 to $10^{\circ} \mathrm{N}$ zonal band (Fig. 16c, d). The dipole pattern completely reverses for the June, July, and August (JJA) mean, which is strongly related to the location of the positive wind stress curl (Fig. 16a, b). The wind change associated with the ITCZ seasonal migration in the eastern tropical Pacific is the main cause of the seasonal variability in this zonal band. For the 2 to $10^{\circ} \mathrm{S}$ zonal band, we see the same signal but it is significantly weaker than the Northern Hemisphere counterpart. As for latitude poleward of $10^{\circ} \mathrm{N}$, the seasonal variation synchronizes across the $\mathrm{Pa}$ cific basin similar to the midlatitude response where the surface net heat flux dominates the changes of seasonal DSL.

\subsection{Rossby wave propagation}

The seasonal variation of DSL in the 2 to $10^{\circ} \mathrm{N}$ zonal band is a result of the Rossby wave propagation that is generated in the eastern and central tropical Pacific by the local wind stress curl (McPhaden et al., 1988). Figure 16 shows 

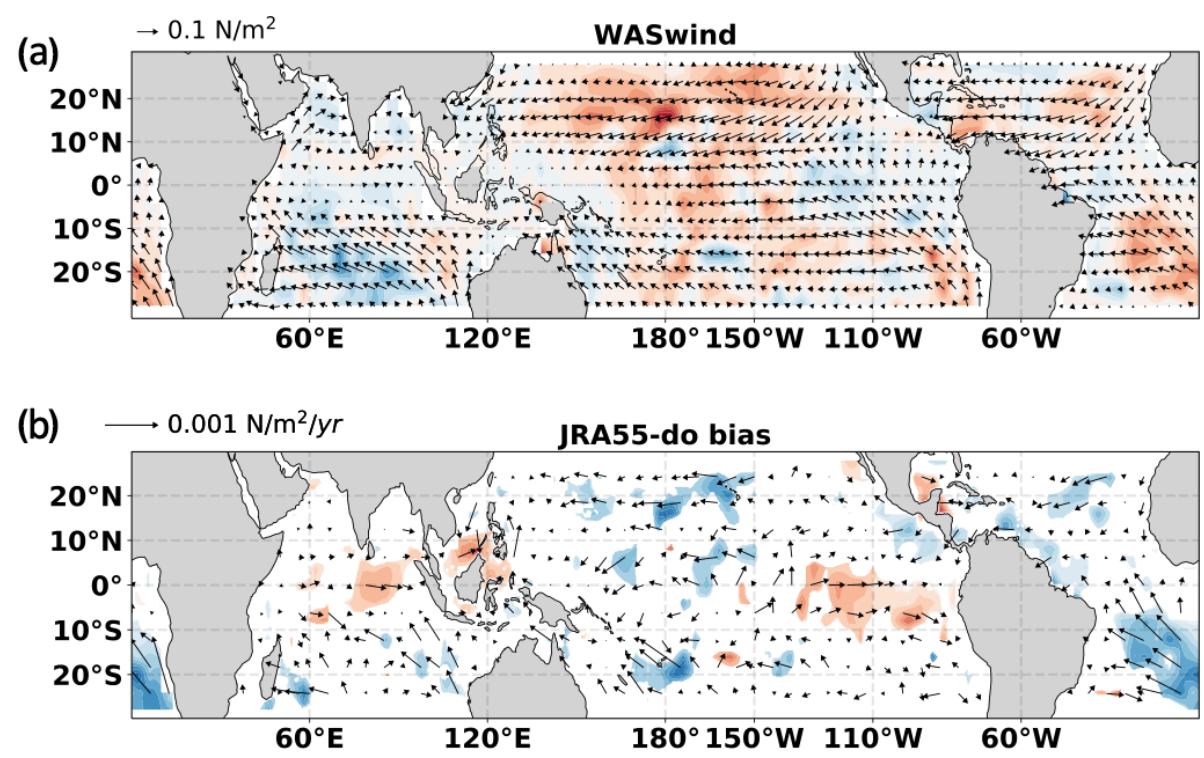

(c)

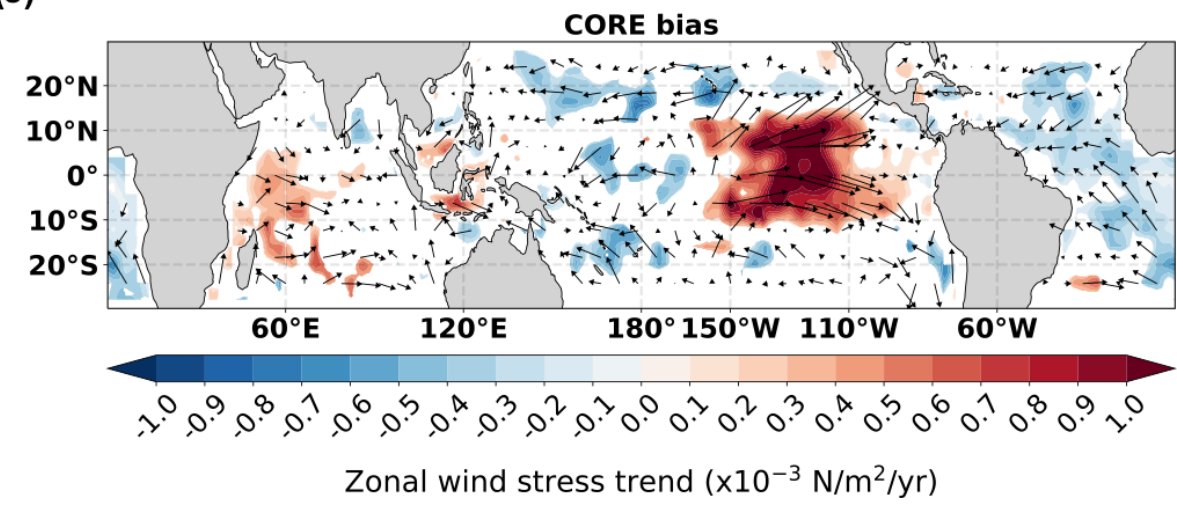

Figure 11. (a) The zonal wind stress trend (shading) and mean state of wind stress (arrow) during 1958-2007 in the observational data (WASwind). (b) The zonal wind stress trend bias (shading) and wind stress trend bias (arrow) over the same period in JRA55-do forcing data. The same as panel (b) but with (c) CORE forcing data. The shading in panels (b, c) shows the trend is statistically significant with $99 \%$ confidence.

the spatial pattern of the wind stress curl anomaly and the DSL anomaly in the eastern tropical Pacific between 2 and $10^{\circ} \mathrm{N}$.

The Hovmöller diagram of the meridional mean from 2 to $10^{\circ} \mathrm{N}$ shows the propagation of this seasonal DSL signal and its relation with the Ekman pumping derived from wind stress curl (Fig. 17). The DSL signal propagation speed matches the theoretical value of the first baroclinic Rossby wave of approximately $0.3 \mathrm{~m} \mathrm{~s}^{-1}$ (Knauss and Garfield, 2016). The calculation is based on Fig. 17 from $110^{\circ} \mathrm{W}$ to $150^{\circ} \mathrm{E}$ from January to December, which also matches with Meyers (1979). A dipole structure appears across the zonal band when the previously generated signal reaches the central Pacific, while a newly generated opposite signal starts in the eastern tropical Pacific. The zonal dipole DSL does not reverse the absolute DSL gradient since the DSL difference between the east and west is $0.6 \mathrm{~m}$ in the mean state, while the Rossby wave created a east-west dipole that has an amplitude of only $0.1 \mathrm{~m}$.

The CORE simulation also shows a larger seasonal DSL bias than JRA55-do. The larger bias in CORE is mainly due to the wrong timing of the wind stress curl in the eastern tropical Pacific. Generally, the seasonal amplitude of DSL forced by CORE is closer to the observed amplitude than JRA55-do. However, the timing of the DSL signal is delayed by 3 months, especially in the initiation region of $90^{\circ} \mathrm{W}$ (Fig. 17). The positive DSL anomaly only starts in May for CORE, while JRA55-do and observations show a positive anomaly as early as February along $90^{\circ} \mathrm{W}$. The DSL lag results in a much longer and larger negative DSL anomaly signal around $100^{\circ} \mathrm{W}$ in the CORE simulation.

The missed timing in CORE is related to the weaker Ekman pumping/suction east of $90^{\circ} \mathrm{W}$ throughout the year, thus causing significant DSL biases compared to observations. 

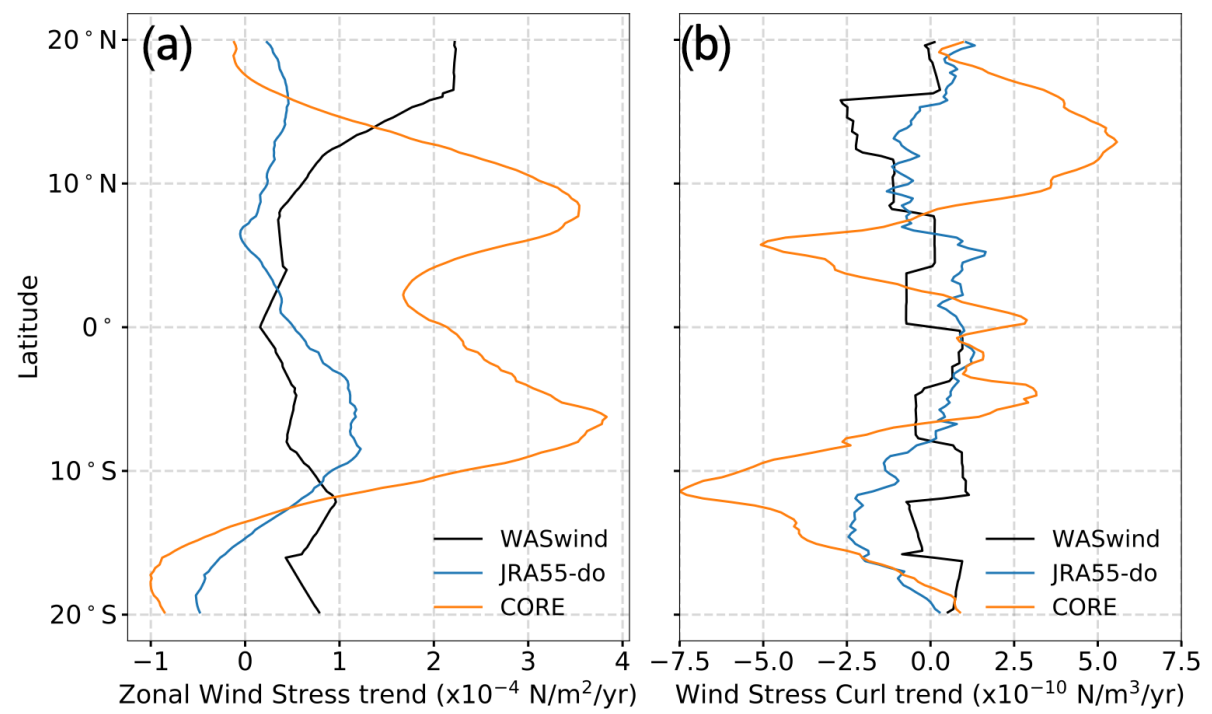

Figure 12. The zonal mean during the 1958-2007 period for (a) zonal wind stress trend and (b) wind stress curl trend over the tropical Pacific basin.

The timing of the JRA55-do simulation is relatively close to observations but with underestimated amplitudes in both Ekman pumping and DSL. This analysis shows the importance of resolving dynamics near the ocean boundary as they can strongly affect the basin-scale DSL variation on seasonal timescales.

Outside the initiation region, both forcing data show weaker Ekman suction during JJA and weaker Ekman pumping during DJF between $150^{\circ} \mathrm{W}$ and $180^{\circ}$ when compared to observations (Fig. 17b, d). The weaker forcing does not affect the propagation of the DSL signal, but it causes the DSL signal in both simulations to be biased low west of $150^{\circ} \mathrm{W}$ due to the lack of continuous external forcing.

The vertical Ekman-induced velocity in the Ekman layer is given by

$W_{\mathrm{E}}=k \cdot \nabla \times\left(\frac{\boldsymbol{\tau}}{\rho_{0} f}\right)=\frac{1}{\rho_{0} f}\left(\frac{\partial \tau_{y}}{\partial x}-\frac{\partial \tau_{x}}{\partial y}+\frac{\tau_{x}}{f} \beta\right)$.

In the tropics, a vertical velocity in the Ekman layer can be generated with zero wind stress curl but strong zonal wind due to the large $\beta$ effect. Therefore, the weaker Ekman suction during JJA and weaker pumping during DJF could be related to the underestimated wind stress curl or zonal wind stress between $150^{\circ} \mathrm{W}$ and $180^{\circ}$. The wind stress curl does not show bias as Ekman pumping/suction bias (Fig. 18f, h). The zonal wind stress, on the other hand, shows the negative bias (easterly bias) during JJA and positive bias (westerly) during DJF between $150^{\circ} \mathrm{W}$ and $180^{\circ}$ in both JRA55do and CORE, which is similar to the bias in Ekman pumping/suction (Fig. 18b, d). This result indicates that the westerly (during JJA) and easterly (during DJF) winds between $150^{\circ} \mathrm{W}$ and $180^{\circ}$ are not strong enough in both JRA55-do and CORE, which leads to the underestimated Ekman suction and pumping, respectively.

The other interesting fact is the compensating effect between zonal wind stress and wind stress curl on the Ekman mechanism in this zonal band. In other words, the first two terms on the right-hand side of Eq. (4) which represent the wind-stress-curl-induced Ekman effect compensate for the last term which represents the zonal-wind-stress-induced Ekman effect. Figure 18 quantitatively visualizes this compensating effect perfectly, which shows the zonal-windrelated Ekman contribution and wind-stress-curl-related Ekman contribution. During JJA, the westerly wind dominates the zonal band due to cross-equatorial flow from the Southern Hemisphere, converging toward the ITCZ located in the Northern Hemisphere (Fig. 16a). The cross-equatorial flow, at the same time, provides a negative wind stress curl with Ekman pumping that compensates the effect of westerly wind on generating the Ekman suction (Fig. 18a, e). During DJF, the easterly component is generated due to the dominant northeasterly wind converging toward the ITCZ with little zonal wind south of the ITCZ (Fig. 16b). The difference in zonal wind near the ITCZ creates a positive wind stress curl with Ekman suction that also compensates the effect of the easterly wind on generating the Ekman pumping. Due to the compensating effect, the bias of zonal wind at around $120^{\circ} \mathrm{W}$ in the CORE simulation is compensated by the bias in wind stress curl (Fig. 18d, h). In other words, the Ekman mechanism at $120^{\circ} \mathrm{W}$ in the CORE simulation, though close to the observations like JRA55-do, is right for the wrong reason. Particularly in the tropical Pacific, this compensation effect should be further examined in the future when evaluating simulations to better understand the underlying biases. 


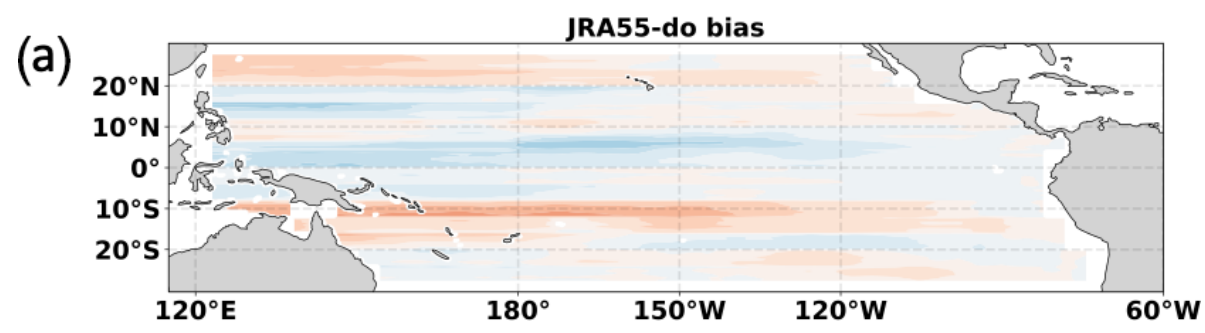

(b)

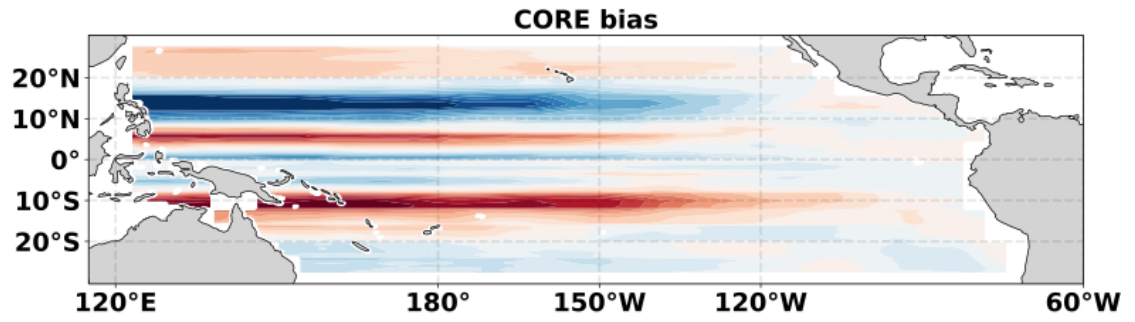

(c)

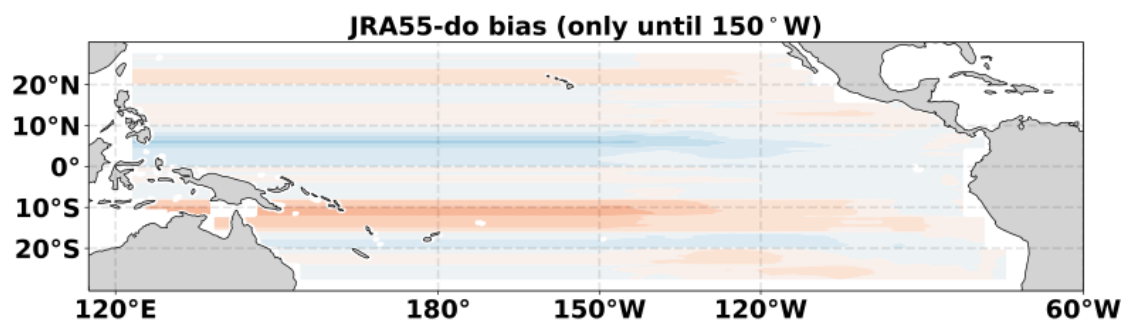

(d)

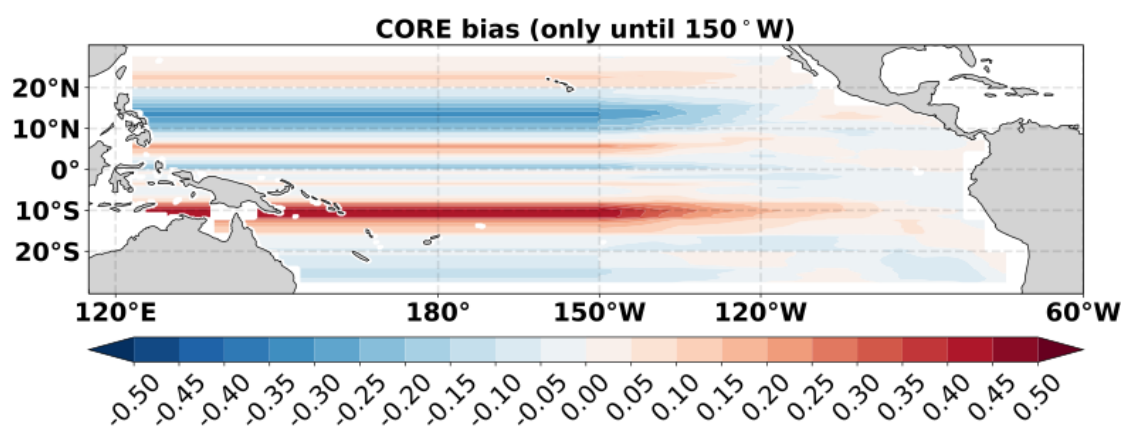

Sverdrup stream function trend (Sv/yr)

Figure 13. The Sverdrup stream function trend bias during the 1958-2007 period in (a) JRA55-do and (b) CORE, which is derived from integration through the whole Pacific basin as is. By changing the value to zero west of $150^{\circ} \mathrm{W}$ to the western boundary, the Sverdrup stream function trend bias is calculated during the same period in (c) JRA55-do and (d) CORE.

\subsection{Surface heat fluxes}

We now examine the thermodynamical contribution from the surface heat flux to the seasonal DSL variation in JRA55-do. The latent heat flux and solar radiation control the net surface heat flux at the seasonal timescale (Fig. 19a-c). At the seasonal timescale, sea surface temperature (SST) is determined by the surface net heat flux with a roughly 3-month time lag (Fig. 19a, d). The mixed layer depth follows the SST which deepens during low SST because of the reduced stratification near the ocean surface and shoals during high
SST because of the enhanced stratification (Fig. 19d, e). This mixed layer pattern can not be used to explain the spatiotemporal pattern seen in DSL seasonal variation (Fig. 17). Instead, we find that the $20^{\circ} \mathrm{C}$ isotherm shows the same wave propagation as the DSL, thus indicating the baroclinic nature of this seasonal Rossby wave propagation and the dominant role of ocean dynamics on the DSL variation. The seasonal analysis over the tropical Pacific shows the important role of ocean dynamics on the DSL variation which is quite different from the midlatitudes where the thermodynamic forcing 

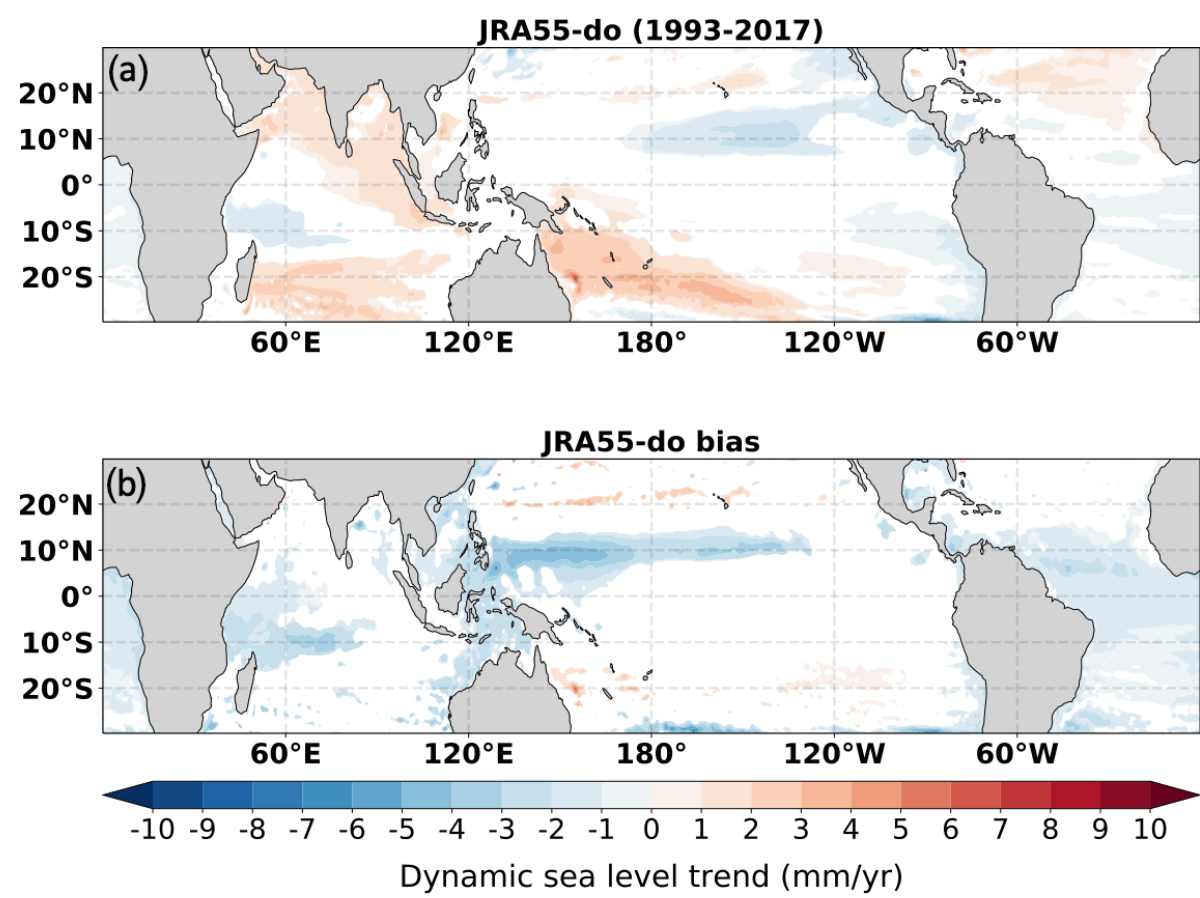

Figure 14. The DSL (a) trend and (b) trend bias during 1993-2017 with $99 \%$ confidence (shading) in the JRA55-do-forced simulation.
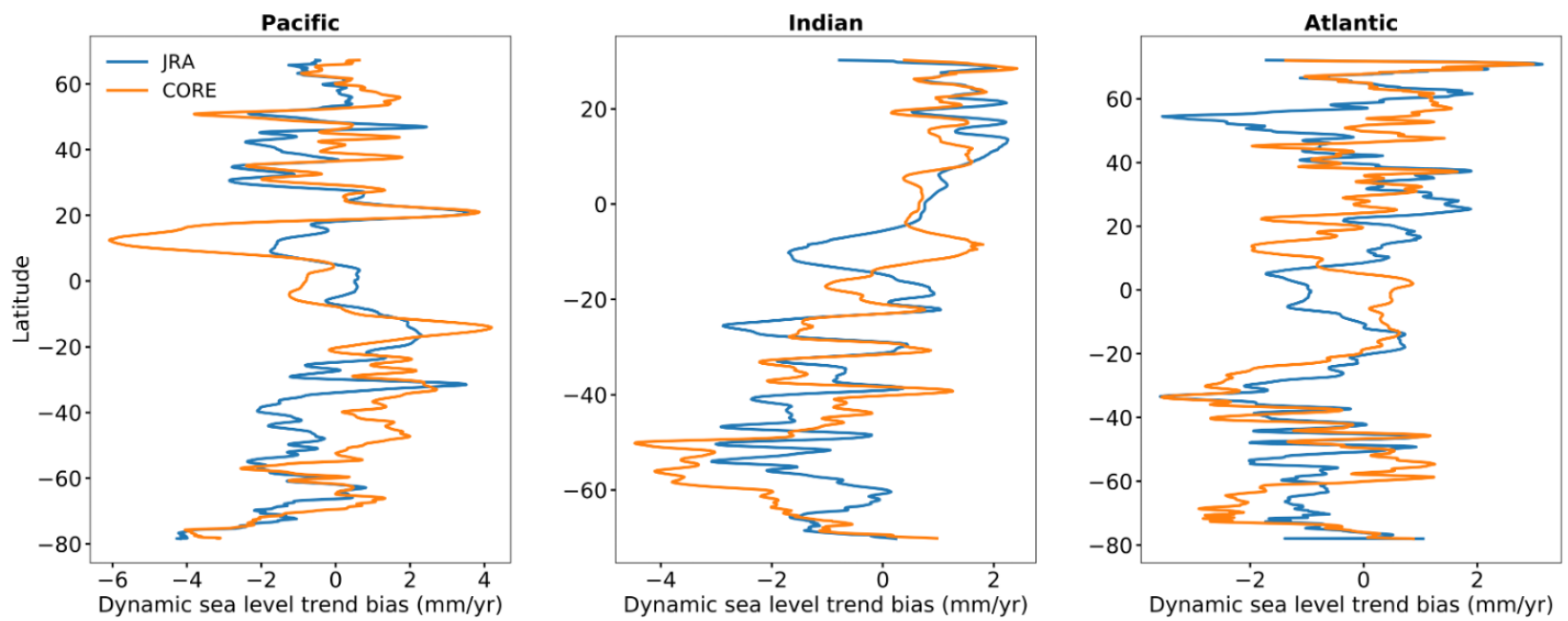

Figure 15. The zonal mean DSL trend bias at all three major basins from JRA55-do (blue) and CORE (orange) forced simulations during 1993-2007.

dominates the changes of seasonal DSL (Vinogradov et al., 2008).

\subsection{Zonal currents}

Due to the significant seasonal fluctuations in DSL within the tropical Pacific, we use the same box budget as in Fig. 5 to study the corresponding zonal current variations between Wbox and Ebox. The zonal current anomaly is strongly affected by the meridional DSL gradient. In the 2 to $10^{\circ} \mathrm{N}$ zonal band, we find one of the largest DSL variances. The corresponding meridional DSL gradient changes, in response to the Rossby wave propagation, can have a large impact on the seasonal changes of the NECC. Figure 20a, b show the seasonal amplitude and phase defined by the largest values of the monthly climatology and the corresponding month, respectively. The SEC and the EUC show comparable and dominating roles on seasonal heat advection between Ebox and Wbox. The seasonal amplitude of heat advection in the CORE simulation is larger than with JRA55-do for all currents, which is consistent with larger wind stress forcing and DSL amplitude in CORE. 


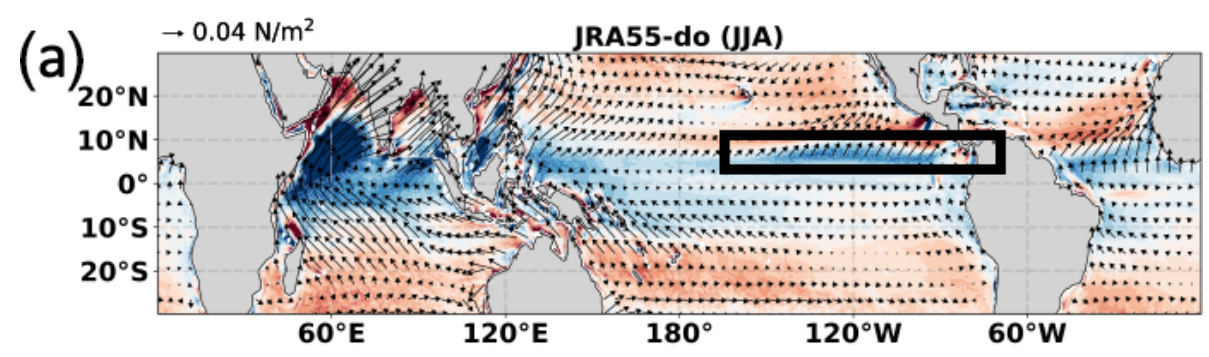

(b)

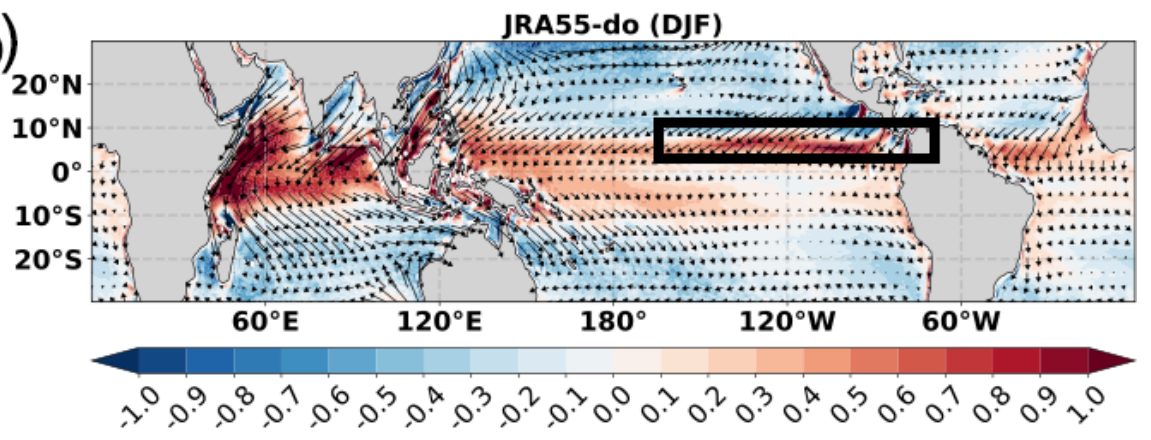

Wind Stress Curl $\left(\times 10^{-7} \mathrm{~N} / \mathrm{m}^{3}\right)$
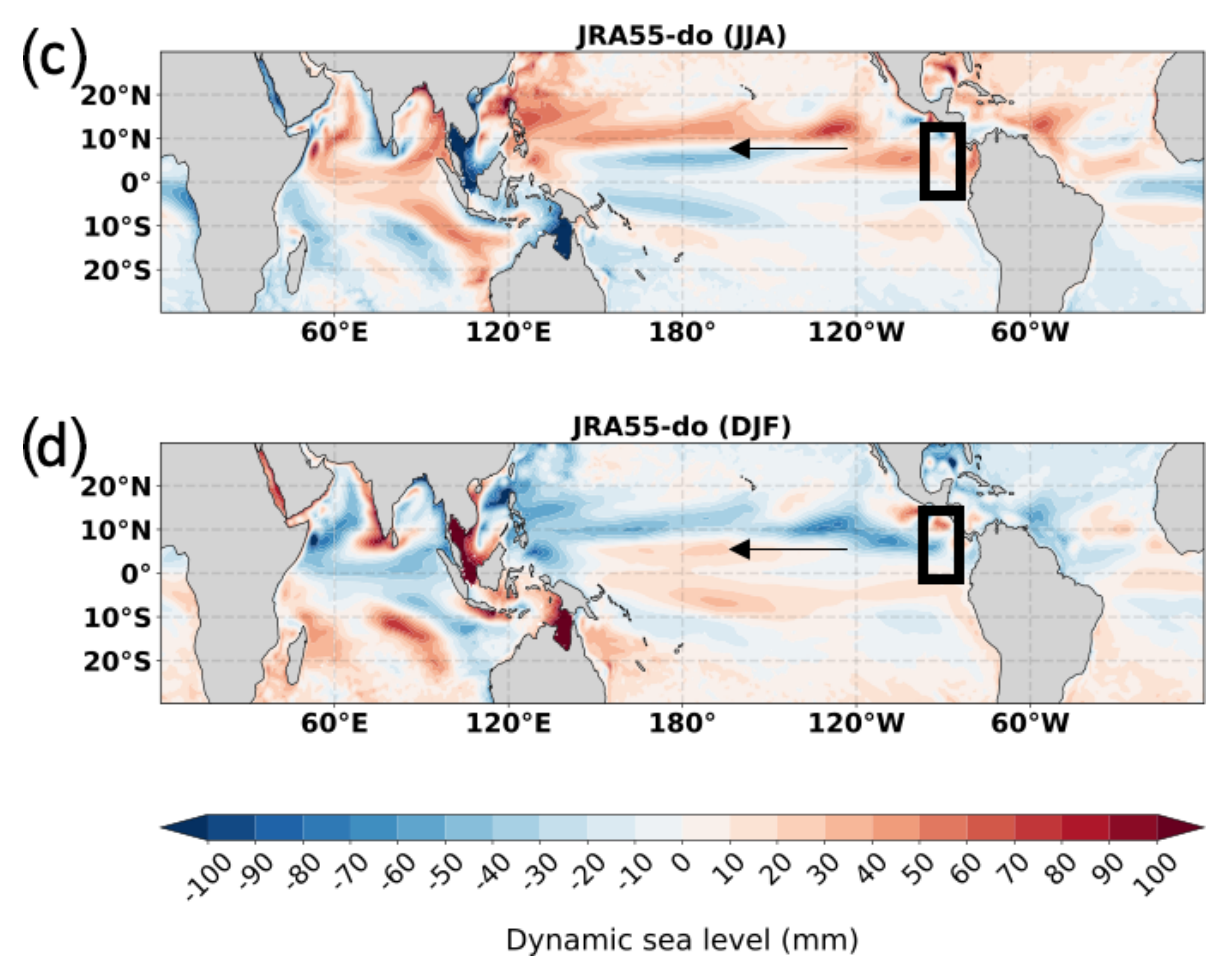

Figure 16. Monthly climatology (1993-2007) of (a) June, July, August (JJA) and (b) December, January, February (DJF) in wind stress (vector) and wind stress curl (shading) from JRA55-do forcing data with mean state removed and the corresponding DSL of the (c) JJA mean and (d) DJF mean from the JRA55-do-forced simulation. The black boxes in panels (a) and (b) show the positive wind stress curl locations which are associated with the ITCZ location in the eastern tropical Pacific. The black arrows in panels (c) and (d) show the Rossby wave propagation directions with the black boxes showing the initiation regions in the eastern tropical Pacific. 

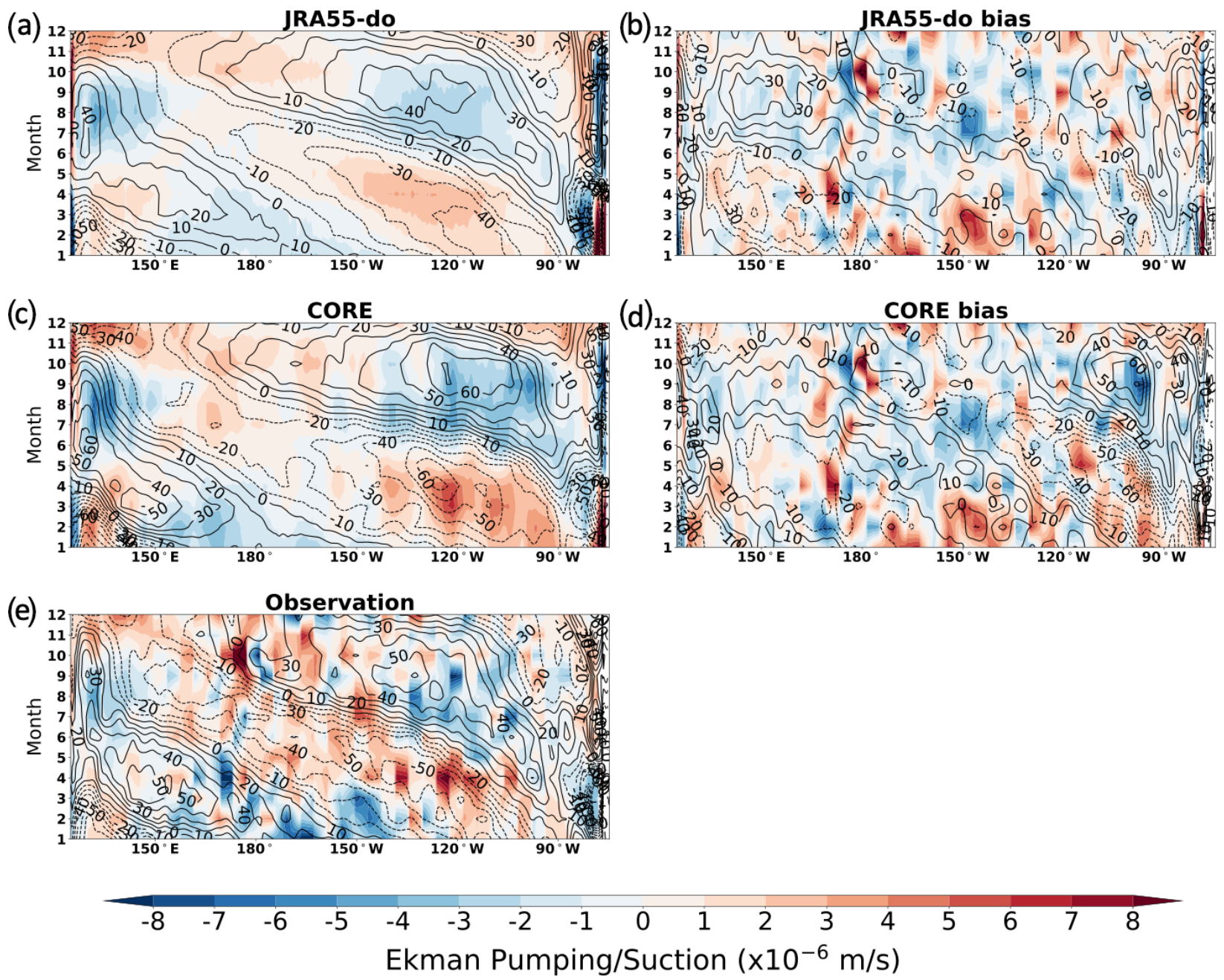

Figure 17. Hovmöller diagram of monthly climatology with mean state removed showing the meridional mean $\left(2\right.$ to $\left.10^{\circ} \mathrm{N}\right)$ DSL (contour in $\mathrm{mm}$ ) and derived Ekman pumping/suction (shading) in (a) JRA55-do-forced simulation and (b) the associated bias, and in the (c) COREforced simulation and (d) the associated bias. (e) The DSL (contour in mm) from CMEMS and derived Ekman pumping/suction (shading) from WASwind.

All seasonal phases agreed between the two simulations except for the NECC and SEC. The SEC difference between the two simulations is mainly due to the small difference in the subseasonal signal that causes the difference in phase (Fig. 20c). For the NECC, the difference in phase can also be seen in the volume transport, which peaks in June for CORE and November for JRA55-do (Fig. 20b, c). The simulation forced by JRA55-do shows a better agreement with the observed NECC, which peaks in December (Johnson et al., 2002). Due to the better simulation of the Rossby wave propagation which affects the DSL seasonal variation in the narrow zonal bend in JRA55-do, the seasonal variation of meridional DSL gradient is also better represented in the simulation which affects the timing of the NECC. At $180^{\circ}$, the positive anomaly of meridional DSL gradient in CORE during the second half of the year creates an anomalous counterforce which counteracts the negative meridional DSL gradi- ent that supports NECC strength (Fig. 21). This effect can also be seen in Fig. 20c, where NECC in the CORE-forced simulation decreases in the second half of the year that deviates from the more accurate NECC simulation forced by JRA55-do.

The zonal current analysis confirms the importance of an accurate simulation of the DSL at the seasonal timescale. This analysis also demonstrates the crucial role of the surface wind stress timing near the eastern tropical Pacific, which influences the timing of heat advection and volume transport across the tropical Pacific. The NECC and SECC, though smaller than SEC and EUC in volume transport, are the only two currents that show a change of direction in the simulation at seasonal timescales (Fig. 20c). This current reversal, however, does not exist in the observations. In the simulations, the current reversals result from the underestimated mean state of the currents that leads to the incorrect seasonal heat 

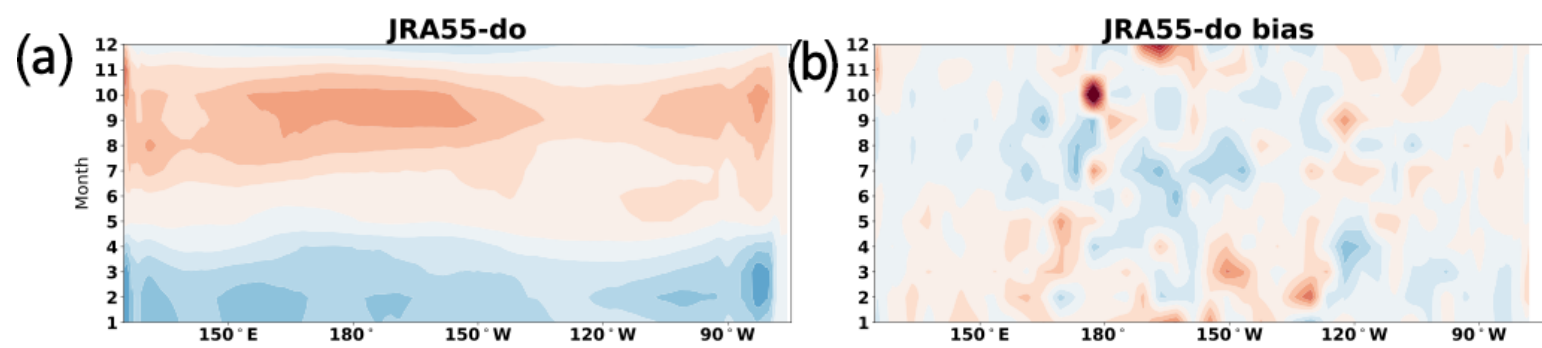

(c)

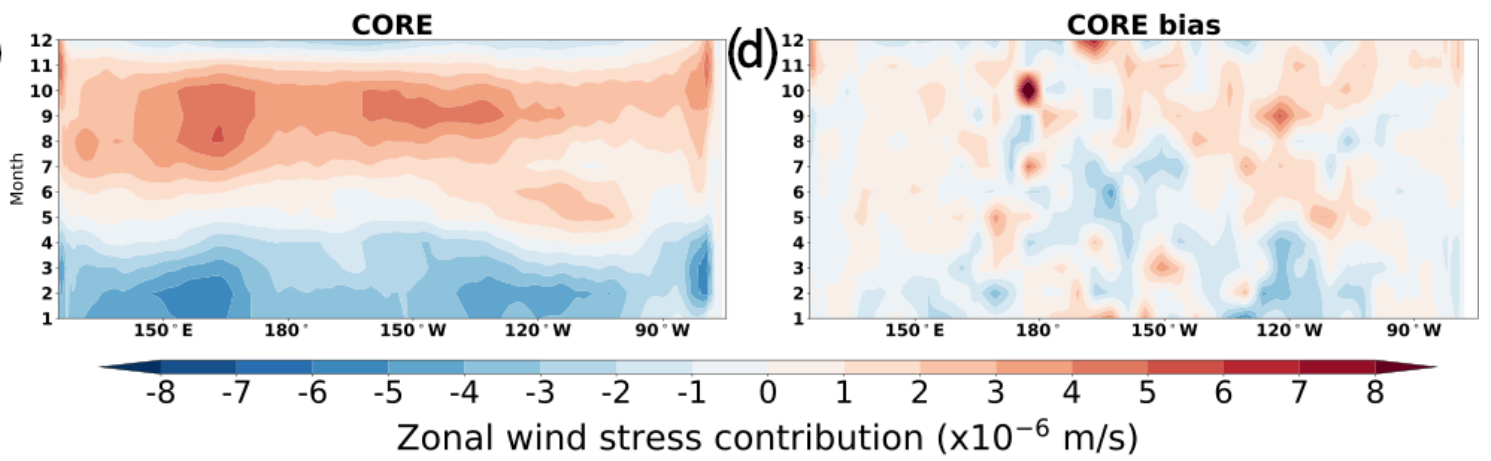

(e)

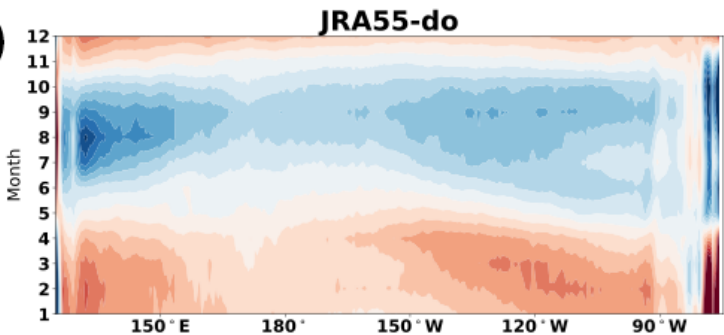

(f)

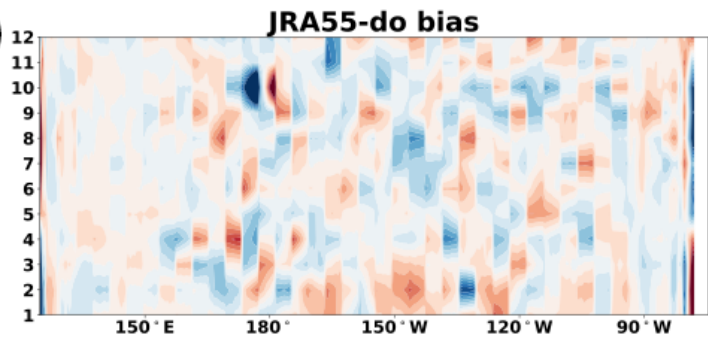

(g)

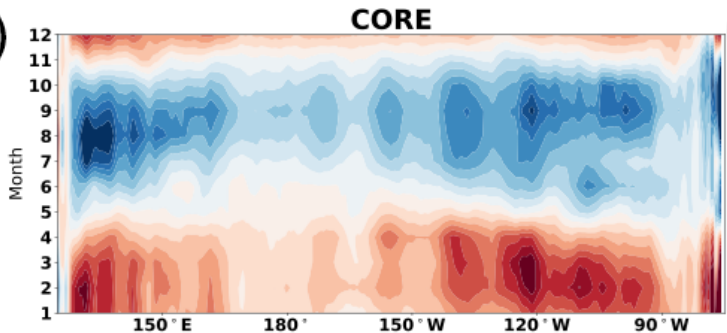

(h)

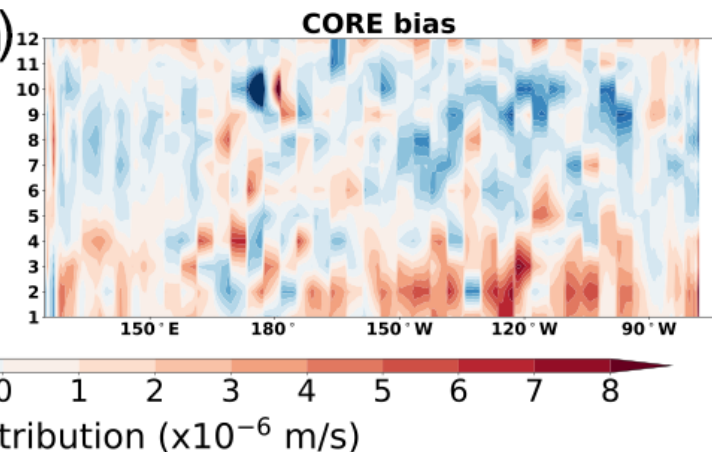

Figure 18. Hovmöller diagram of monthly climatology with mean state removed showing the meridional mean $\left(2\right.$ to $\left.10^{\circ} \mathrm{N}\right)$ of $(\mathbf{a})$ zonalwind-stress-induced Ekman pumping/suction in JRA55-do forcing and (b) the associated bias, (c) zonal-wind-stress-induced Ekman pumping/suction in CORE forcing and (d) the associated bias, (e) wind-stress-curl-induced Ekman pumping/suction in JRA55-do forcing and (f) the associated bias, and (g) wind-stress-curl-induced Ekman pumping/suction in CORE forcing and (h) the associated bias.

and mass transport direction. However, due to the small contribution in volume and heat budgets from these two currents, the model simulation is not greatly affected by this reversal at the seasonal timescale.

\section{Dynamic sea level variability during EI Niño}

Besides the seasonal variation, one of the largest DSL fluctuations over the tropical Pacific is related to the El NiñoSouthern Oscillation (ENSO) at the interannual timescale. To investigate the DSL bias during El Niño, we first define and find all El Niño events in both simulations. We use the Oceanic Niño index (ONI) to find all El Niño events dur- 

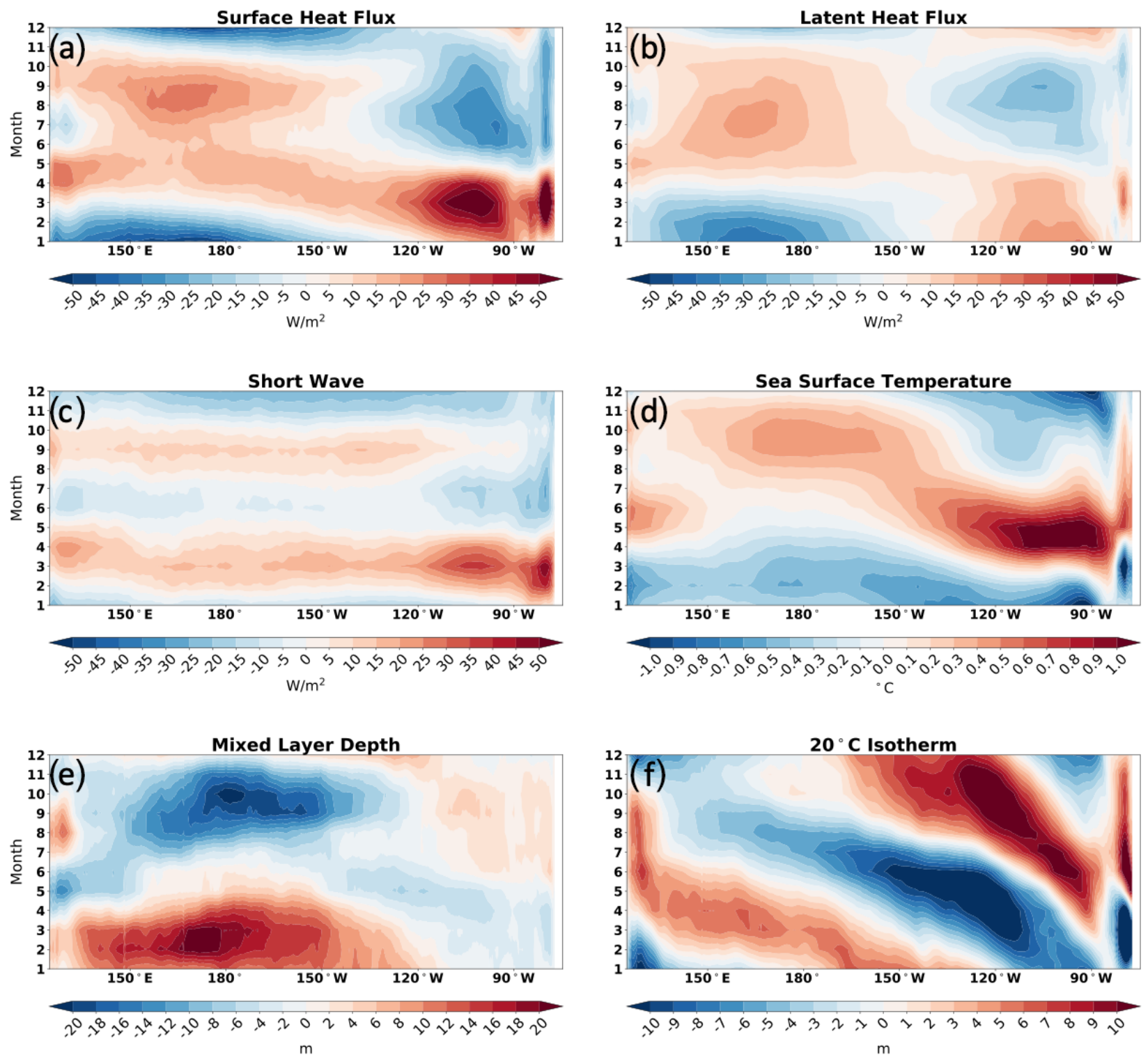

Figure 19. Hovmöller diagram of monthly climatology (1993-2007) with mean state removed showing the meridional mean (2 to $\left.10^{\circ} \mathrm{N}\right)$ of (a) surface net heat flux, (b) latent heat flux, (c) shortwave radiative flux, (d) sea surface temperature, (e) mixed layer depth, and (f) $20^{\circ} \mathrm{C}$ isotherm from the JRA55-do-forced simulation.

ing 1958-2007. To obtain the ONI, we calculate the areaweighted mean of monthly SST anomalies in the Niño3.4 region $\left(5^{\circ} \mathrm{N}-5^{\circ} \mathrm{S}, 170-120^{\circ} \mathrm{W}\right)$ with seasonal climatology and long-term trend removed before calculating the 3 -month running mean. The detrending follows the method from the Climate Prediction Center at NOAA by removing the 30-year means from every 5 years centered at the 30-year window. The El Niño event is defined when ONI has five consecutive values that are larger than $0.5^{\circ} \mathrm{C}$ and ends when the ONI is lower than $0.5^{\circ} \mathrm{C}$. Both simulations show good agreement with the observed ONI (Fig. 22a). To better describe El Niño stages, we define Year0, Year1, and Year2 based on the composite El Niño period (Fig. 22b), where Year1 winter is when
ONI reaches its maximum, Year0 is 1 year before Year1, and Year2 is the year following Year1. A composite of DSL and wind stress from simulations and observations is calculated based on a total of 12 El Niño events during the 1958-2007 period (Fig. 22b). To determine the composite, we remove the mean, trend, and seasonal signals in all of the time series.

\subsection{Oscillator theories}

We first focus on the zonal mean of the DSL variation in the tropical Pacific region during El Niño. A clear rechargedischarge oscillator affecting DSL can be seen evolving during El Niño (Fig. 23a, c, e) (Jin, 1997). According to the 
(a)

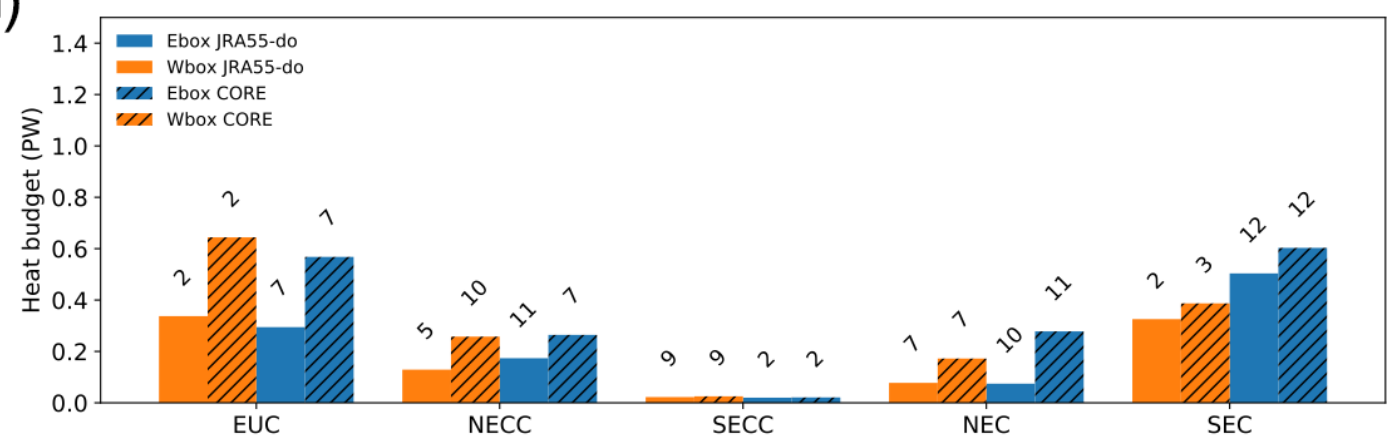

(b)

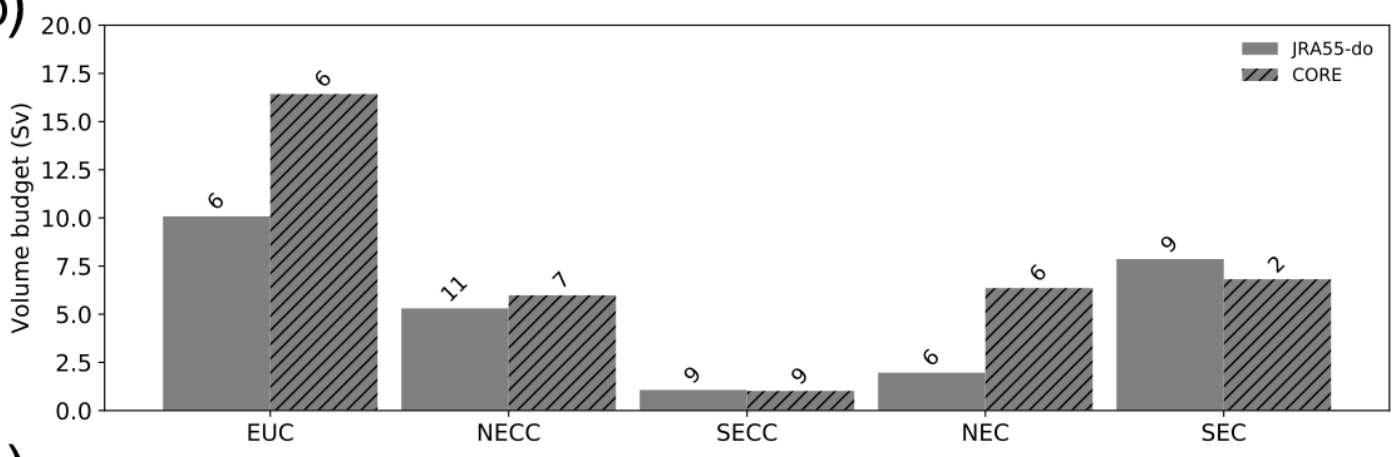

(c)

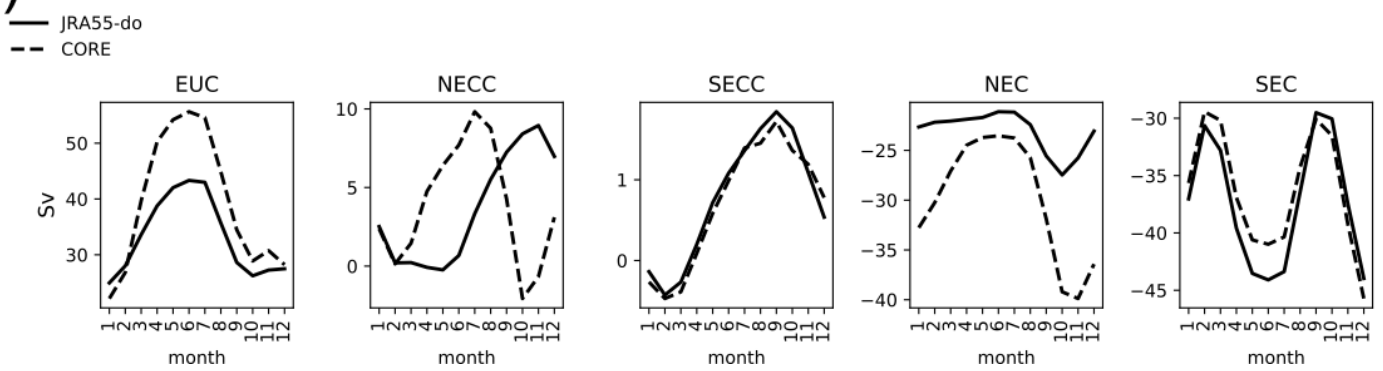

Figure 20. The seasonal amplitude (bar) and phase (integer which represents the month on top of each bar) of (a) heat advection to the Wbox (yellow bar) and Ebox (blue bar) across the $180^{\circ}$ transect and (b) the volume transport (gray bar) from individual current. The JRA55do-forced simulation (no stripe) and the CORE-forced simulation (striped) are placed side by side for comparison. Panel (c) indicates the seasonal variation of volume transport from JRA55-do (solid) and CORE (dashed) for each current.

oscillator theory, the warm water volume continues to be charged into the equatorial region before it reaches the peak of an El Niño. It then discharges to higher latitude after the peak as a result of the Sverdrup transport response to wind forcing over the tropical Pacific. The SST lags the DSL positive anomaly before the peak and the negative anomaly after the peak of El Niño. This lag means that the subsurface processes build up the warm water volume before the SST starts to warm up during the charging stage. During the discharging stage, the subsurface processes release the warm water volume before the SST starts to cool down.

Consistent with the theory, DSL reaches the peak at the end of Year1 for both simulations during the charging stage, which increase the warm water volume near the Equator, and quickly changes to a negative anomaly, while the higher lati- tude changes from a negative to positive anomaly, which indicates the start of the discharging stage (Fig. 23a, c). The lag of the SST is also clear in both simulations. The CORE simulation shows a larger DSL bias which is consistent with the bias shown at other timescales (Fig. 23b, d). The rechargedischarge pattern can also be seen during the longer period composite (1958-2007) (Fig. 23e).

We separate the El Niño period into four different stages (Fig. 24). The first is the initiation stage calculated as the mean of 7 months to 12 months prior to the maximum ONI (February, Year1 to July, Year1). In this stage, we see the positive DSL anomaly initiated in the central tropical $\mathrm{Pa}$ cific along the Equator. The second stage is the mean of 6 months prior to the maximum ONI value (August, Year1 to January, Year2). The positive DSL anomaly propagates east- 


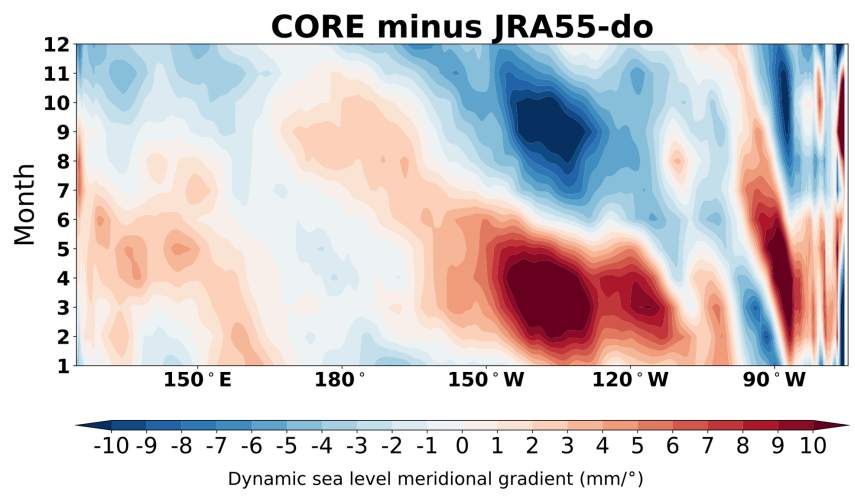

Figure 21. Hovmöller diagram of monthly climatology (19932007) with mean state removed showing the meridional mean (2 to $10^{\circ} \mathrm{N}$ ) of the DSL gradient (shading in $\mathrm{mm} /$ degree) difference by subtracting the JRA55-do-forced simulation from CORE.

ward due to the propagation of an equatorial downwelling Kelvin wave, while the negative DSL anomaly strengthens in the western tropical Pacific in both hemispheres (Zebiak and Cane, 1987). Based on the ENSO oscillator theories, the negative DSL anomaly in the western tropical Pacific is a result of two phenomena. One is the upwelling Rossby wave propagating westward on two sides of the Equator reaching the western boundary based on the delayed oscillator theory (Zebiak and Cane, 1987). The other is related to the shoaling of the off-Equator thermocline based on the western tropical Pacific oscillator theory (Weisberg and Wang, 1997). The latter also leads to the increase of sea level pressure due to decreasing SST and the associated easterly wind at the Equator in the third stage.

The third stage is the mean of 6 months following the maximum ONI value (January, Year2 to June, Year2). The positive anomaly in the eastern Pacific starts to dissipate through a coastal Kelvin wave moving heat toward the poles (Johnson and O'Brien, 1990). The reflected downwelling Rossby wave on two sides of the Equator, on the other hand, tries to move the heat back to the warm pool in the western Pacific (Picaut et al., 1997). Like in stage 2, the DSL drop in stage 3 over the western tropical Pacific is also a result of two phenomena. Based on the delay oscillator theory, the reflected upwelling Rossby-wave-related DSL drop in the western tropical Pacific starts showing at the Equator. On the other hand, the western tropical Pacific oscillator theory emphasizes the importance of equatorial easterly winds, due to the positive sea level pressure off-Equator, on generating the negative DSL anomaly at the Equator. This stage is also referring to the discharging stage in the recharge-discharge oscillator theory where the warm water volume is discharged poleward from the Equator. The final stage is calculated as the mean of 7 months to 12 months following the maximum ONI value (July, Year2 to December, Year2). In the final stage, the downwelling Rossby wave on two sides of the Equator shows in the western tropical Pacific for both simulations.

In general, the model simulations show great resemblance in terms of spatial patterns and temporal changes. Both simulations demonstrate the oscillator theories well. However, asymmetry in the DSL changes on two sides of the Equator seem missing from the theories mentioned above during El Niño. The asymmetric pattern, like the negative DSL signal in the southwestern tropical Pacific, is related to other mechanisms dominating the DSL signal over certain regions, which reduces the symmetry along the Equator (McGregor et al., 2012).

\subsection{Asymmetry in the dynamic sea level along Equator}

The negative DSL anomaly and the asymmetry of DSL in the southwestern tropical Pacific are not due to the lack of discharging of warm water from the Equator but instead due to the drop in DSL signal that is intensified after the peak ONI (stage 3) (Fig. 24e, f). This dropping DSL signal can also be found in the composite based on observations during 1993 2007 (Fig. 25). We see that the Southern Hemisphere DSL drop is strongly related to the pressure difference between Australia and the Southern Hemisphere central to eastern tropical Pacific (Fig. 26). This pressure difference, known as the Southern Oscillation Index (SOI), causes a negative wind stress curl in the region of DSL drop in stage 2 (Fig. 26c, d) and stage 3 (Fig. 26e, f), which results in Ekman suction and the associated negative DSL anomaly.

The negative DSL anomaly in the southwest tropical Pacific started before the ONI peak (stage 2) and reached maximum right after the peak (stage 3) (Fig. 24). In stage 2, a high-pressure center is established near Australia, while a low-pressure center is formed near the southeast tropical Pacific (Fig. 26c,d). Between the two pressure systems, a strong geostrophic wind toward the Equator is formed and turns to the right near the Equator due to the low pressure at the eastern equatorial Pacific. This turning creates a negative wind stress curl in the southwestern tropical Pacific that causes Ekman suction and the associated negative DSL anomaly.

After the ONI peak, a low-pressure center is established in the south-central tropical Pacific (Fig. 26e, f). This lowpressure center, closer to the southwest tropical Pacific than in stage 2, causes a stronger negative wind stress curl than in stage 2 due to the increased pressure gradient that results in stronger Ekman suction and DSL drop. Eventually, the dropping DSL signal subsides due to decreased and reversed pressure contrast related to the Southern Oscillation (Fig. 26g, h). Since the composite based on observations only includes four El Niño events, the different sea level pressure amplitudes could be readily dominated by the strongest events. Therefore, the amplitude changes between longer (1958-2007) and shorter periods (1993-2007) should not be seen as a longterm trend but instead a sign of possible decadal variability of the ENSO/SOI strength. 
(a)

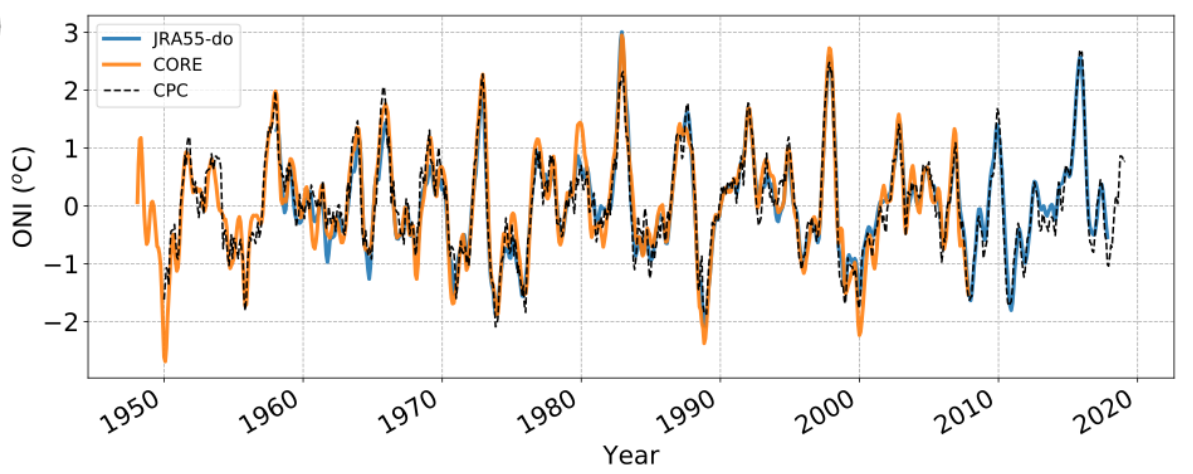

(b)

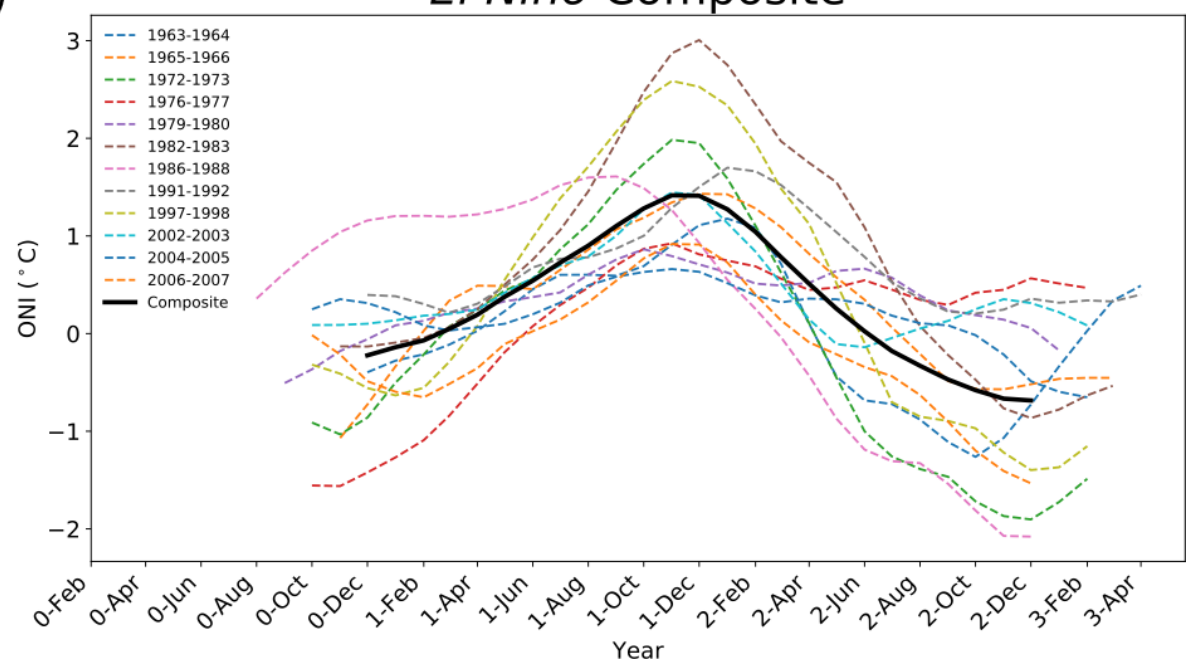

Figure 22. (a) The Ocean Niño Index (ONI) in JRA55-do (solid blue), CORE (solid orange), and observation provided by the Climate Prediction Center at the National Oceanic and Atmospheric Administration (dashed black). (b) All El Niño events picked out during the period of 1958-2007 to calculate the El Niño composite.

The mechanism of the asymmetric sea level along Equator is missing in the known oscillator theories. The delayed oscillator theory can explain the DSL drop in the western tropical Pacific resulting from a westward propagation of upwelling Rossby wave in stage 2 . The western tropical Pacific oscillator, on the other hand, emphasizes the importance of dropping SST in the western tropical Pacific due to the shoaling of the thermocline (dropping DSL) as a result of cyclonic wind generated from off-equatorial convection in stage 2 . (Deser and Wallace, 1990; Weisberg and Wang, 1997). Both theories cannot explain the maximum value of DSL drop in stage 3 in the Southern Hemisphere and the asymmetric response of DSL and sea level pressure between the north and south.

To better quantify the role of the wind stress curl on the DSL variation in the tropical Pacific during the composite period, we regress the wind stress curl with the DSL anomaly at each grid point (Fig. 27). Figure 27b, d show the strong positive correlation $(R>0.6)$ between DSL and wind stress curl in the region where the negative DSL anomaly is located (Fig. 24) in both JRA55-do and CORE simula- tions. The regression shows a regression coefficient of around $1.2 \times 10^{-8} \mathrm{~N} \mathrm{~m}^{-3}$ per $10 \mathrm{~mm}$ DSL change. Compared to the Southern Hemisphere, the maximum DSL drop in the Northern Hemisphere happens in stage 2. This drop is quickly restored toward the mean state in stage 3 (Fig. 24) due to an increase of negative wind stress curl created by the high sea level pressure (Fig. 26), which is a process described by the western tropical Pacific oscillator theory (Weisberg and Wang, 1997). This behavior is also shown in the regression maps where the wind stress curl is negatively correlated with the DSL anomaly in the region from $150^{\circ} \mathrm{E}$ to $180^{\circ}$ and Equator to $20^{\circ} \mathrm{N}$.

This analysis demonstrates the importance of sea level pressure evolution in the tropical Pacific on the DSL changes during El Niño. In stage 2, the combination of ocean wave propagation (delayed oscillator) and wind stress curl creates the maximum DSL drop in the northwest tropical Pacific. In stage 3, the air-sea interaction (western tropical Pacific oscillator) quickly restores the northwest tropical Pacific DSL to the mean state through the established high sea level pressure, while the negative wind stress curl established by the 

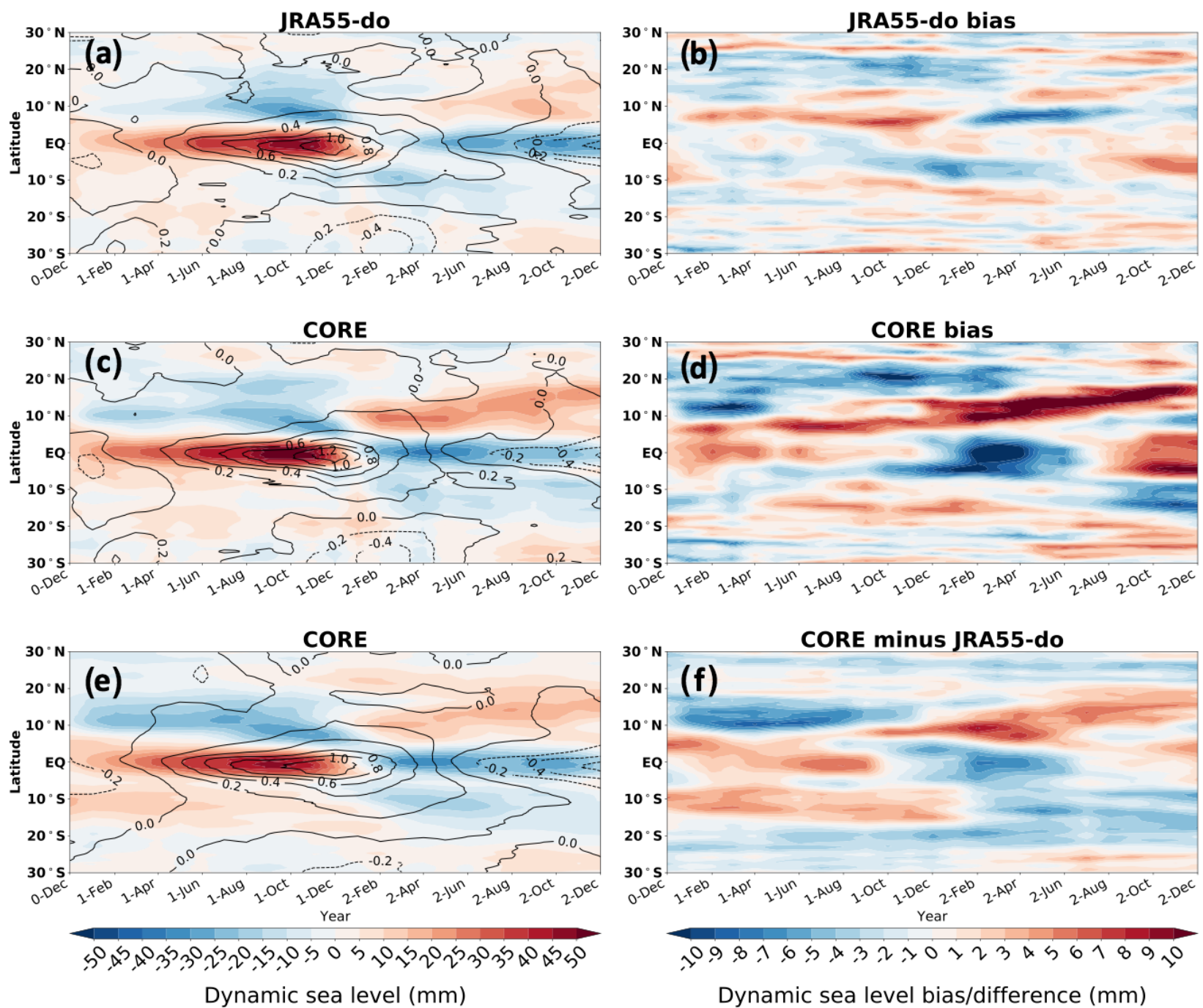

Figure 23. Hovmöller diagram showing the zonal mean over the tropical Pacific basin during the El Niño composite (1993-2007 with a total of four El Niño events) in the (a) JRA55-do-simulated DSL variation (shading), sea surface temperature (contour with unit ${ }^{\circ} \mathrm{C}$ ), and (b) the associated DSL bias, and the (c) CORE-simulated DSL variation (shading), sea surface temperature (contour with unit ${ }^{\circ} \mathrm{C}$ ), and (d) the associated DSL bias. (e) Hovmöller diagram of the zonal mean over the tropical Pacific during the El Niño composite (1958-2007 with a total of $12 \mathrm{El} \mathrm{Niño} \mathrm{events)} \mathrm{in} \mathrm{the} \mathrm{CORE-simulated} \mathrm{DSL} \mathrm{variation} \mathrm{(shading),} \mathrm{sea} \mathrm{surface} \mathrm{temperature} \mathrm{(contour} \mathrm{with} \mathrm{unit}{ }^{\circ} \mathrm{C}$ ), and (f) the JRA55-do-simulated DSL subtracted from CORE.

sea level pressure gradient in the Southern Hemisphere creates the maximum DSL drop in the southwest tropical Pacific. The different mechanisms between north and south indicate the lag in DSL signal is due to different forcings. It is not an energy redistribution or wave propagation between the northwestern and southwestern tropical Pacific. This asymmetry in the DSL dropping signal between the north and south of the western tropical Pacific can usually be seen during El Niño.

\section{$7 \quad$ Summary and conclusions}

In this study, we use the GFDL-OM4 global ocean-sea ice model, as forced by JRA55-do and CORE, to investigate the DSL variability and the associated biases compared to available observational datasets. We are able to show the improvement found with the JRA55-do forcing used in OMIPII relative to the CORE forcing in OMIP-I. We also reveal needed future improvements in the forcing across different timescales. 

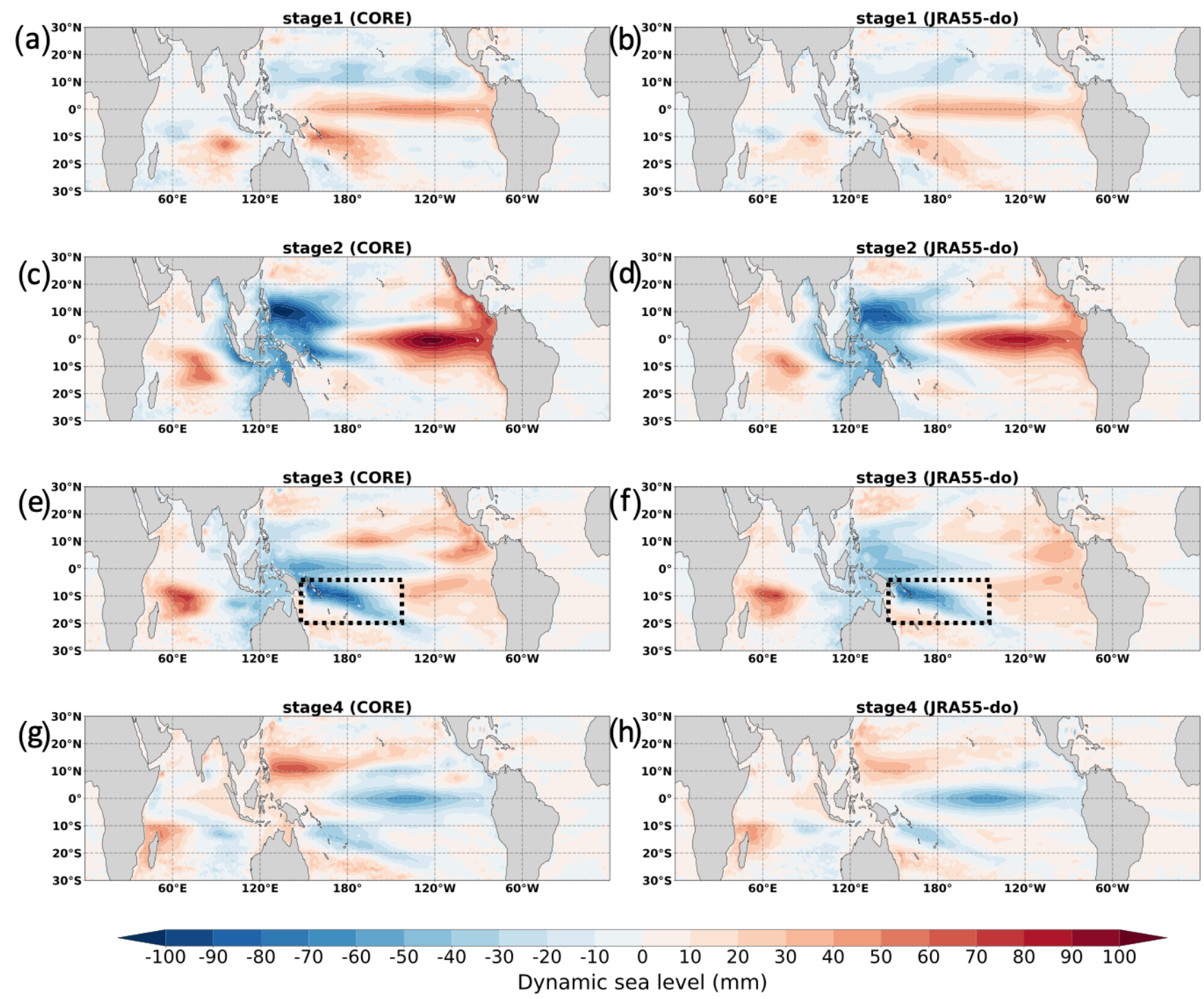

Figure 24. The DSL anomaly during the El Niño composite as determined during 1958-2007 in four different stages. The first row shows the first stage (the mean of 7-12 months prior to the maximum ONI value) in (a) CORE and (b) JRA55-do. The second row shows the second stage (the mean of 6 months prior to the maximum ONI value) in (c) CORE and (d) JRA55-do. The third row shows the third stage (the mean of 6 months following the maximum ONI value) in (e) CORE and (f) JRA55-do. The dashed black boxes show the region of asymmetric sea level changes in the southwestern tropical Pacific. The last row shows the fourth stage (the mean of 7-12 months following the maximum ONI value) in (g) CORE and (h) JRA55-do.

\subsection{Summary}

The mean state bias of DSL persists in the simulations forced by JRA55-do when compared to CORE. The missing DSL trough along $9^{\circ} \mathrm{N}$ in both CORE- and JRA55-do-forced simulations shows the importance of sharp zonal wind stress changes near the ITCZ. In the $4^{\circ} \mathrm{N}$ to $9^{\circ} \mathrm{N}$ latitude band, the bias in the wind stress forcing causes flattening of the DSL gradient in the meridional direction that leads to biases in the geostrophic current. The bias in the geostrophic current directly impacts the mean strength of NECC and NEC. A future improvement of the zonal wind shear in the tropical
Pacific is needed for a better DSL and zonal current representation in ocean model simulations.

The JRA55-do-forced simulation significantly improves the DSL trend bias over the tropical Pacific. The improved zonal wind stress trend in JRA55-do over the eastern equatorial Pacific is the main reason for the better DSL trend simulations. The trend analysis shows extra attention is needed for the method used for correcting the magnitude of the wind stresses found in reanalysis data. A single multiplicative factor applied to the entire time series of wind stress may not be appropriate since it can cause errors in variability and changes in other timescales. A DSL trend bias along $10^{\circ} \mathrm{N}$, 
(a)

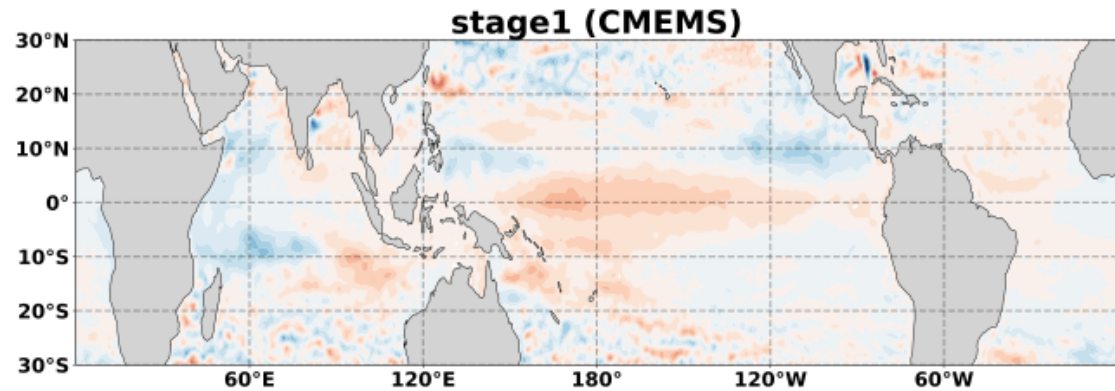

(b)

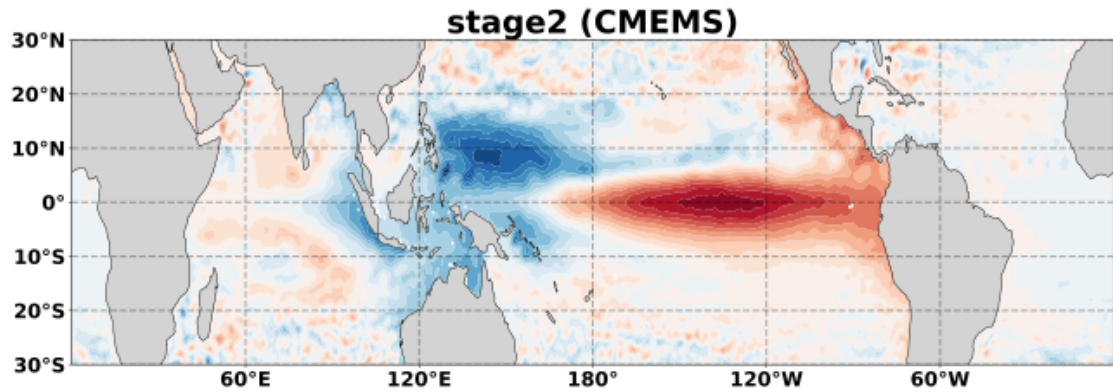

(c)

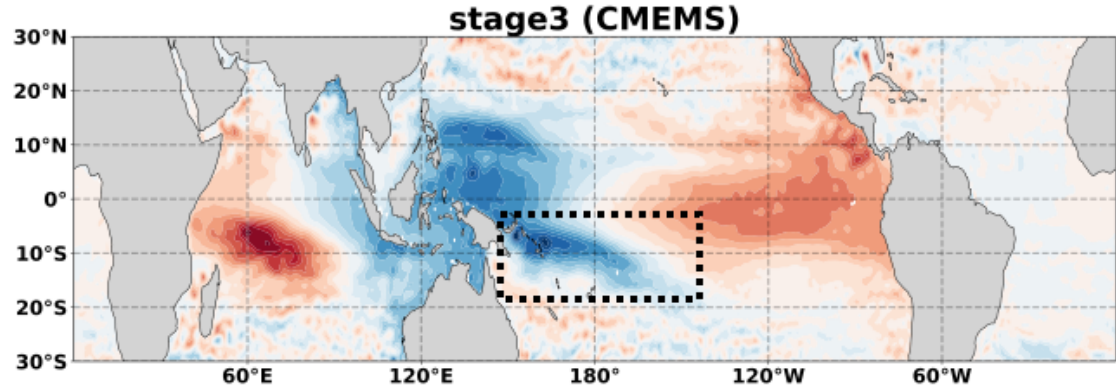

(d)

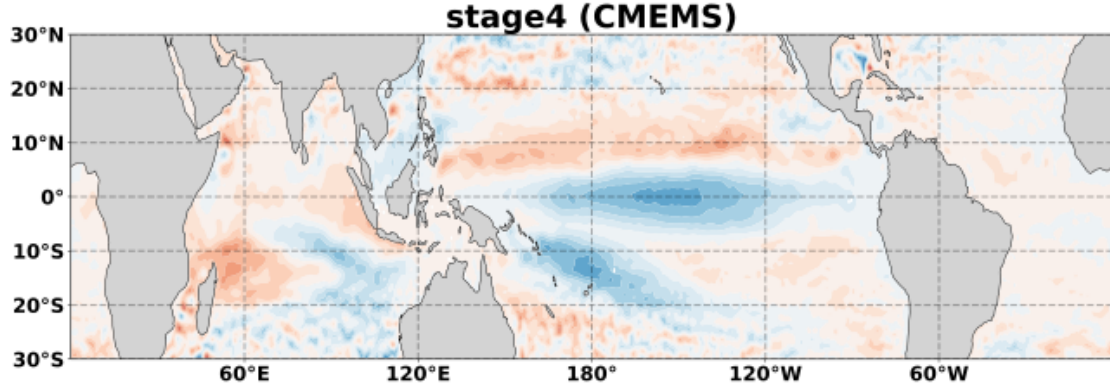

$-100-90-80-70-60-50-40-30-20-10 \quad 0 \quad 10203040506070 \quad 8090100$

Dynamic sea level $(\mathrm{mm})$

Figure 25. The DSL evolution from satellite altimeter observation in four different stages (top to bottom) during the El Niño composite (1993-2007) defined in Fig. 24. The dashed black box shows the region of asymmetric sea level change in the southwestern tropical Pacific at stage 3 . 
(a)

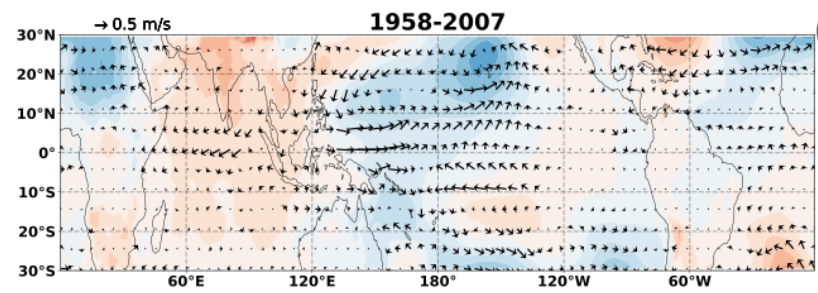

(b) 3

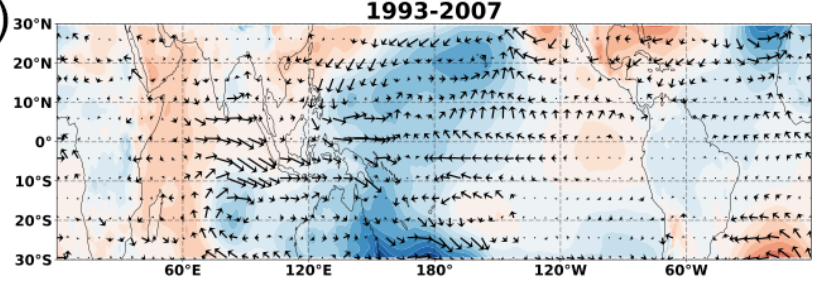

(c)

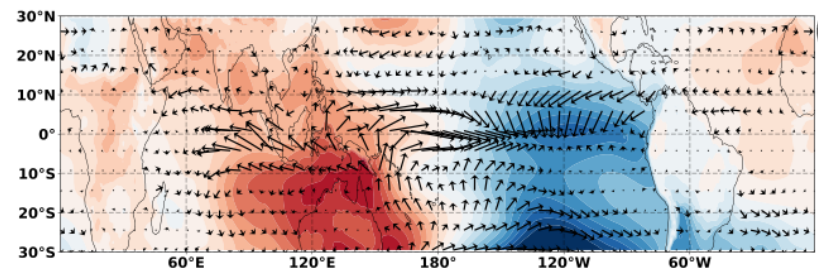

$(d)^{30}$

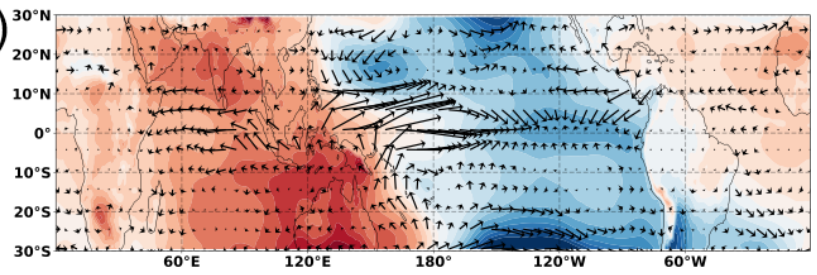

(e)

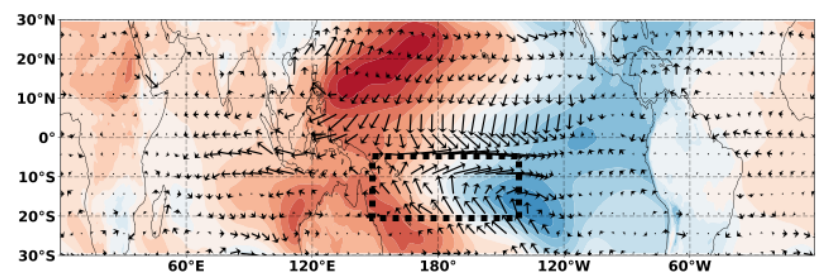

$(\mathrm{f})^{30}$

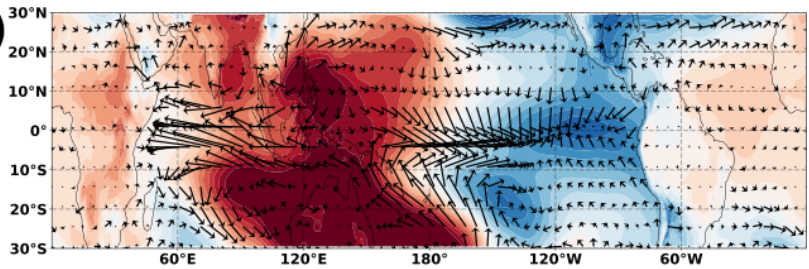

(g)
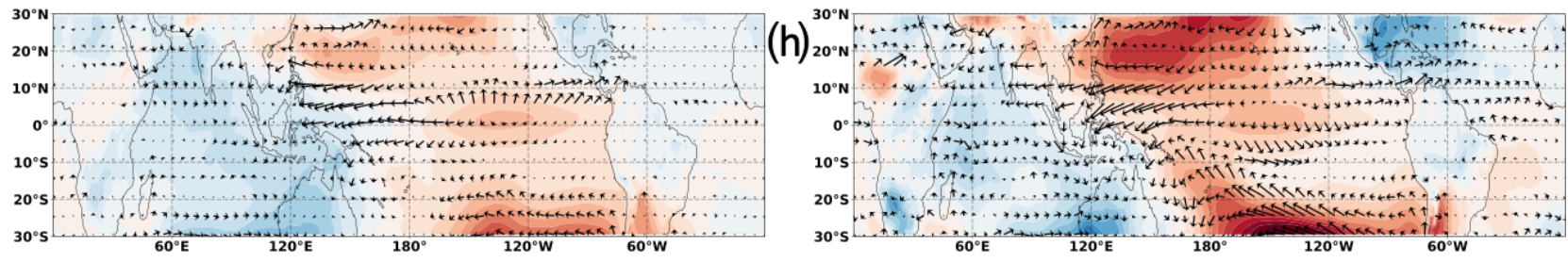

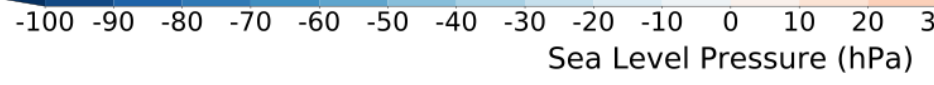

Figure 26. The sea level pressure (shading) and surface wind (vector) from JRA55-do forcing in four different stages (top to bottom), defined in Fig. 24, during the El Niño composite determined over (a, c, e, g) 1958-2007 and (b, d, f, h) 1993-2007. The dashed black box shows the region of asymmetric sea level change in the southwestern tropical Pacific at stage 3.

though improved, still exists in the JRA55-do-forced simulation. We identify an easterly wind trend bias, related to this persisting DSL trend bias in both CORE and JRA55-do, as a point of focus for improvements in the atmospheric forcing.

The JRA55-do-forced simulation also shows improved seasonal DSL variation due to a better representation of the wind stress curl forcing in the eastern tropical Pacific. The improved timing of wind stress curl in JRA55-do results in a more accurate Rossby wave propagation in the $0-10^{\circ} \mathrm{N}$ zonal band, thus leading to an improved NECC simulation. In this zonal band, both zonal wind stress and wind stress curl contribute to the Ekman pumping/suction with compensating effects at the seasonal timescale. Though the final effect of Ekman pumping/suction in CORE is similar to that in JRA55do, the CORE forcing data have a relatively inaccurate repre- sentation of the zonal wind and wind stress curl. The reason for the similar Ekman pumping/suction is mainly due to the compensation effect in CORE between the bias in the zonal wind and the bias in wind stress curl. Detailed tropical ocean analysis is needed on the effect of Ekman pumping/suction in future model evaluation to avoid ignoring this bias compensation.

Both CORE and JRA55-do generate reasonable DSL variations during El Niño compared to observations, with smaller biases in the JRA55-do simulation. An asymmetry in the DSL change during an El Niño event on two sides of the Equator has not been explained in the existing oscillator theories. We find the asymmetry in the DSL pattern is strongly related to wind stress curl that follows the sea level pressure evolution during El Niño. An atmospheric sea level pressure 

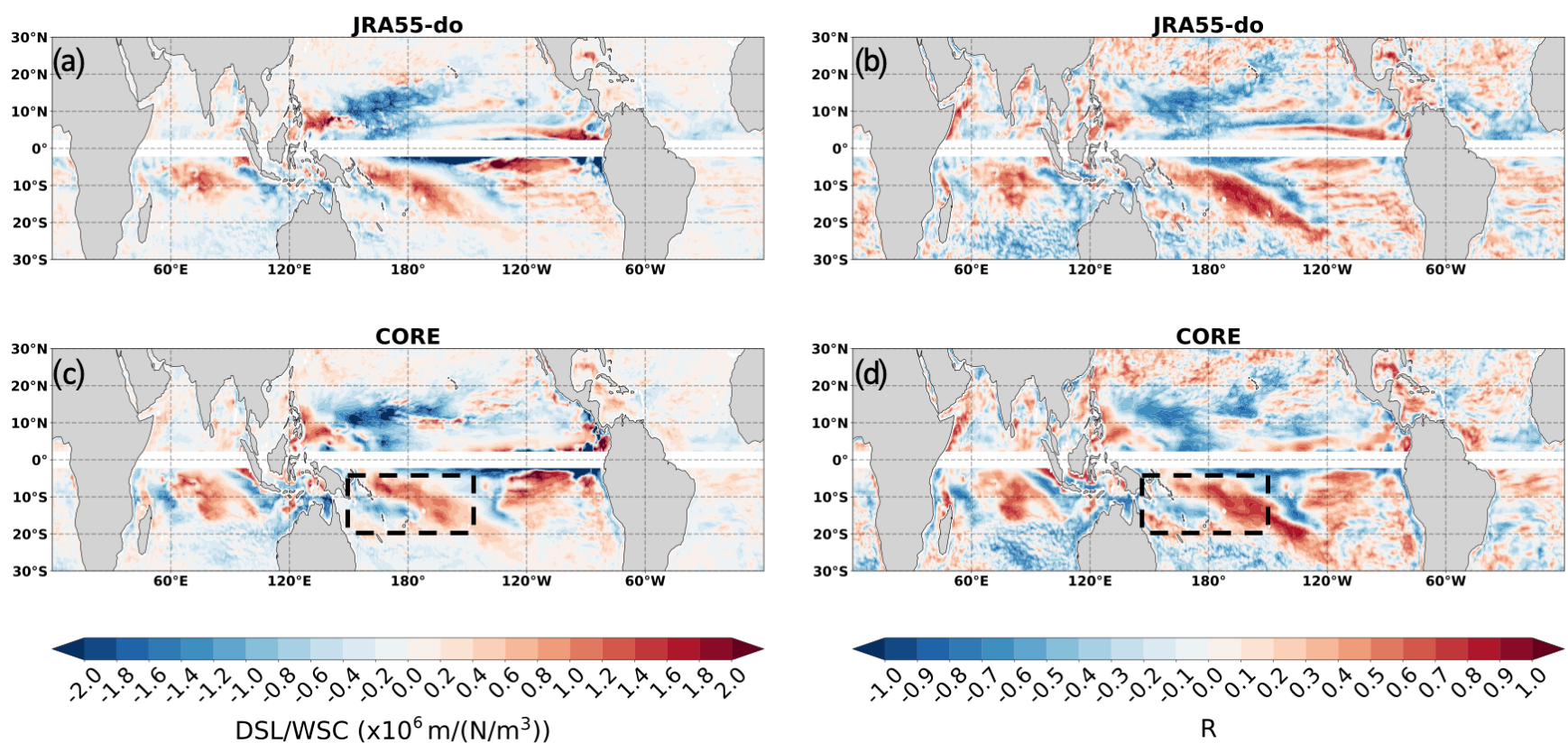

Figure 27. The regression coefficients between wind stress curl and DSL anomaly during the El Niño composite (1958-2007) in (a) JRA55do and (c) CORE. The $R$ value from the regression in (b) JRA55-do and (d) CORE. The dashed black boxes show the region of asymmetric sea level changes in the southwestern tropical Pacific.

gradient created by a pressure drop in the southeastern tropical Pacific and a pressure rise in Australia as well as the sea level pressure drop in the cold tongue region are the main contributors to the negative wind stress curl that drives the DSL drop. The high correlation between wind stress curl and DSL shows the dominant influence of local wind forcing on the DSL signal. The analysis demonstrates the importance of the external forcing on the off-Equator DSL changes during an El Niño event.

\subsection{Recommendations for key bias reductions}

To reduce the time-mean bias of DSL in future OMIP simulations over the tropical Pacific, accurate zonal wind stress shear near the ITCZ is crucial. Especially over the 4 to $9^{\circ} \mathrm{N}$ zonal band, the biases in the time mean of the DSL can further affect the mean ocean current strength and cause an artificial seasonal ocean current reversal.

For the bias in the long-term trend of DSL, the JRA55-do has significantly improved the westerly wind bias at the eastern Pacific near the equatorial region $\left(10^{\circ} \mathrm{S}\right.$ to $\left.10^{\circ} \mathrm{N}\right)$ that results in the reduction of DSL bias along $10^{\circ} \mathrm{N}$. To further reduce this DSL bias along $10^{\circ} \mathrm{N}$, we find easterly trend biases exist along $20^{\circ} \mathrm{N}$ in both the JRA55-do and CORE forcings that create the artificial positive wind stress curl along $10^{\circ} \mathrm{N}$, resulting in the negative sea level bias. The multiplicative factor applied to correct the wind stress is highly related to the wind stress bias. A careful evaluation of the wind stress field across different timescales after applying the factor is necessary to reduce the bias of the simulated DSL.
For the seasonal variation of the DSL, the dominant external forcing is region specific. Over the deep tropics, from the Equator to around $10^{\circ} \mathrm{N} / \mathrm{S}$, ocean dynamics are the dominating factor which was mainly initiated at the eastern boundary near $90^{\circ} \mathrm{W}$ due to Ekman suction/pumping induced by local wind stress curl. Therefore, capturing the timing and strength of the local wind stress curl is crucial to better simulate the seasonal variation of the DSL. The accurate DSL variation can further improve the simulated ocean current in seasonal timescale, like the improved NECC in the JRA55do compared to the CORE-forced simulation. However, the continuously underestimated DSL amplitude in the JRA55do simulation, which is related to the underestimated wind stress curl in the same zonal band, needs further improvement. Besides the local boundary wind forcing near $90^{\circ} \mathrm{W}$, the underestimated seasonal zonal wind stress variability between $150^{\circ} \mathrm{W}$ and $180^{\circ}$ in both JRA55-do and CORE causes the underestimated DSL signal throughout the year. Due to the compensation effect of zonal wind stress and wind stress curl on the strength of Ekman suction/pumping in the tropics, a separated evaluation of both zonal wind stress and wind stress curl is needed in the future to avoid the compensated bias shown in the CORE forcing data.

For interannual variability, the El Niño-related DSL variation is well represented in JRA55-do and CORE for both the timing and the spatial pattern. However, we still see a amplitude bias for DSL in both CORE- and JRA55-do-forced simulations. JRA55-do does improve the amplitude bias compared to CORE. 
The multiple timescale analyses in this study provide a comprehensive view of important variability, changes, and the associated biases in the tropical Pacific. Any improvement of the biases mentioned in this study will be very helpful to further a mechanistic understanding of tropical Pacific DSL patterns using OMIP simulations and by extension their related coupled climate models.

Code and data availability. The Python scripts used to generate the figures in this study are available on GitHub (https://github.com/chiaweh2/OMIP_TropPac_SeaLevel and Zenodo https://doi.org/10.5281/zenodo.4725993, Hsu, 2021). The forcing dataset, JRA55-do, is available through input4MIPs (https: //esgf-node.1lnl.gov/search/input4mips/, Durack et al., 2020). The observed sea surface height is from Copernicus Marine Environment Monitoring Service (CMEMS) (https://resources.marine. copernicus.eu/, Pujol and Mertz, 2019). The EN4 dataset is from the Met Office Hadley Centre (https://www.metoffice.gov.uk/hadobs/ en4/, last access: 13 August 2019, Good et al., 2013). The Wave and Anemometer-based Sea Surface Wind was downloaded from Kyushu University (https://www.riam.kyushu-u.ac.jp/oed/tokinaga/ waswind.html, last access: 19 August 2019, Tokinaga and Xie, 2011). An archive for all of the model outputs is available through the CMIP6 project under OMIP (https://esgf-node.llnl.gov/search/ cmip6/, Griffies et al., 2016).

Author contributions. CWH, JY, and SMG proposed and led this evaluation study. CWH performed the analyses, including processing the model outputs and observational data. RD produced the model outputs. All authors contributed to the writing and editing processes.

Competing interests. The authors declare that they have no conflict of interest.

Acknowledgements. We thank Rebecca Beadling and Andrew Wittenberg for very useful comments on an earlier draft of the manuscript. We are grateful for the input from the two anonymous referees and thank them for their help in improving the manuscript. We acknowledge the World Climate Research Programme coordinating CMIP6 and the related activities like OMIP and input4mips. We are grateful for the archiving effort of the Earth System Grid Federation. We thank the EU Copernicus Marine Service Information for providing the sea surface height data from multiple satellite altimetry measurements. We thank the Met Office Hadley Centre for archiving the temperature and salinity data. We thank Hiroki Tokinaga for processing and archiving the WASwind data.

Financial support. This research has been supported by the Climate Program Office (grant no. NA18OAR4310267).
Review statement. This paper was edited by Qiang Wang and reviewed by two anonymous referees.

\section{References}

Adcroft, A., Anderson, W., Balaji, V., Blanton, C., Bushuk, M., Dufour, C. O., Dunne, J. P., Griffies, S. M., Hallberg, R., Harrison, M. J., Held, I. M., Jansen, M. F., John, J. G., Krasting, J. P., Langenhorst, A. R., Legg, S., Liang, Z., McHugh, C., Radhakrishnan, A., Reichl, B. G., Rosati, T., Samuels, B. L., Shao, A., Stouffer, R., Winton, M., Wittenberg, A. T., Xiang, B., Zadeh, N., and Zhang, R.: The GFDL Global Ocean and Sea Ice Model OM4.0: Model Description and Simulation Features, J. Adv. Model Earth Sy., 11, 3167-3211, https://doi.org/10.1029/2019MS001726, 2019.

Bromirski, P. D., Miller, A. J., Flick, R. E., and Auad, G.: Dynamical Suppression of Sea Level Rise along the Pacific Coast of North America: Indications for Imminent Acceleration, J. Geophys. Res.-Oceans, 116, C07005, https://doi.org/10.1029/2010JC006759, 2011.

Busalacchi, A. J. and Cane, M. A.: Hindcasts of Sea Level Variations during the 1982-83 El Niño, J. Phys. Oceanogr., 15, 213-221, https://doi.org/10.1175/15200485(1985)015<0213:HOSLVD>2.0.CO;2, 1985.

Cane, M. A.: Modeling Sea Level During El Niño, J. Phys. Oceanogr., 14, 1864-1874, https://doi.org/10.1175/15200485(1984)014<1864:MSLDEN>2.0.CO;2, 1984.

Chassignet, E. P., Smith, L. T., Halliwell, G. R., and Bleck, R.: North Atlantic Simulations with the Hybrid Coordinate Ocean Model (HYCOM): Impact of the Vertical Coordinate Choice, Reference Pressure, and Thermobaricity, J. Phys. Oceanogr., 33, 2504-2526, https://doi.org/10.1175/15200485(2003)033<2504:NASWTH>2.0.CO;2, 2003.

Deser, C. and Wallace, J. M.: Large-Scale Atmospheric Circulation Features of Warm and Cold Episodes in the Tropical Pacific, J. Climate, 3, 1254-1281, https://doi.org/10.1175/15200442(1990)003<1254:LSACFO>2.0.CO;2, 1990.

Durack, P. J., Taylor, K. E., Eyring, V., Ames, S. K., Hoang, T., Nadeau, D., Doutriaux, C., Stockhause, M., and Gleckler, P. J.: input4MIPs: Making CMIP Model Forcing more transparent, available at: https://esgf-node.llnl.gov/search/input4mips/, last access: 26 May 2020.

Eyring, V., Bony, S., Meehl, G. A., Senior, C. A., Stevens, B., Stouffer, R. J., and Taylor, K. E.: Overview of the Coupled Model Intercomparison Project Phase 6 (CMIP6) experimental design and organization, Geosci. Model Dev., 9, 1937-1958, https://doi.org/10.5194/gmd-9-1937-2016, 2016.

Gill, A. E. and Niller, P. P.: The Theory of the Seasonal Variability in the Ocean, Deep-Sea Res. Abstracts, 20, 141-177, https://doi.org/10.1016/0011-7471(73)90049-1, 1973.

Good, S. A., Martin, M. J., and Rayner, N. A.: EN4: Quality Controlled Ocean Temperature and Salinity Profiles and Monthly Objective Analyses with Uncertainty Estimates: THE EN4 DATA SET, J. Geophys. Res.-Oceans, 118, 6704-6716, https://doi.org/10.1002/2013JC009067, 2013.

Gregory, J., Griffies, S. M., Hughes, C., Lowe, J., Church, J., Fukimori, I., Gomez, N., Kopp, R., Landerer, F., Ponte, R., Stammer, D., Tamisiea, M., and van den Wal, R.: Concepts and terminology 
for sea level-mean, variability and change, both local and global, Surv. Geophys., 40, 1251-1289, https://doi.org/10.1007/s10712019-09555-7, 2019.

Griffies, S. M., Biastoch, A., Böning, C., Bryan, F., Danabasoglu, G., Chassignet, E. P., England, M. H., Gerdes, R., Haak, H., Hallberg, R. W., Hazeleger, W., Jungclaus, J., Large, W. G., Madec, G., Pirani, A., Samuels, B. L., Scheinert, M., Gupta, A. S., Severijns, C. A., Simmons, H. L., Treguier, A. M., Winton, M., Yeager, S., and Yin, J.: Coordinated Ocean-Ice Reference Experiments (COREs), Ocean Model., 26, 1-46, https://doi.org/10.1016/j.ocemod.2008.08.007, 2009.

Griffies, S. M., Yin, J., Durack, P. J., Goddard, P., Bates, S. C., Behrens, E., Bentsen, M., Bi, D., Biastoch, A., Böning, C. W., Bozec, A., Chassignet, E., Danabasoglu, G., Danilov, S., Domingues, C. M., Drange, H., Farneti, R., Fernandez, E., Greatbatch, R. J., Holland, D. M., Ilicak, M., Large, W. G., Lorbacher, K., Lu, J., Marsland, S. J., Mishra, A., George Nurser, A. J., Salas y Mélia, D., Palter, J. B., Samuels, B. L., Schröter, J., Schwarzkopf, F. U., Sidorenko, D., Treguier, A. M., Tseng, Y.-H., Tsujino, H., Uotila, P., Valcke, S., Voldoire, A., Wang, Q., Winton, M., and Zhang, X.: An Assessment of Global and Regional Sea Level for Years 1993-2007 in a Suite of Interannual CORE-II Simulations, Ocean Model., 78, 35-89, https://doi.org/10.1016/j.ocemod.2014.03.004, 2014.

Griffies, S. M., Danabasoglu, G., Durack, P. J., Adcroft, A. J., Balaji, V., Böning, C. W., Chassignet, E. P., Curchitser, E., Deshayes, J., Drange, H., Fox-Kemper, B., Gleckler, P. J., Gregory, J. M., Haak, H., Hallberg, R. W., Heimbach, P., Hewitt, H. T., Holland, D. M., Ilyina, T., Jungclaus, J. H., Komuro, Y., Krasting, J. P., Large, W. G., Marsland, S. J., Masina, S., McDougall, T. J., Nurser, A. J. G., Orr, J. C., Pirani, A., Qiao, F., Stouffer, R. J., Taylor, K. E., Treguier, A. M., Tsujino, H., Uotila, P., Valdivieso, M., Wang, Q., Winton, M., and Yeager, S. G.: OMIP contribution to CMIP6: experimental and diagnostic protocol for the physical component of the Ocean Model Intercomparison Project, Geosci. Model Dev., 9, 3231-3296, https://doi.org/10.5194/gmd-9-32312016, 2016.

Hamlington, B. D., Strassburg, M. W., Leben, R. R., Han, W., Nerem, R. S., and Kim, K.-Y.: Uncovering an Anthropogenic Sea-Level Rise Signal in the Pacific Ocean, Nat. Clim. Change, 4, 782-785, https://doi.org/10.1038/nclimate2307, 2014.

Hamlington, B. D., Frederikse, T., Nerem, R. S., Fasullo, J. T., and Adhikari, S.: Investigating the Acceleration of Regional Sea Level Rise During the Satellite Altimeter Era, Geophys. Res. Lett., 47, e2019GL086528, https://doi.org/10.1029/2019GL086528, 2020.

Holmes, R. M., Zika, J. D., and England, M. H.: Diathermal Heat Transport in a Global Ocean Model, J. Phys. Oceanogr., 49, 141161, https://doi.org/10.1175/JPO-D-18-0098.1, 2019.

Hsu, C.-W.: chiaweh2/OMIP_TropPac_SeaLevel: GMD publication release (Version v1.0), Zenodo, https://doi.org/10.5281/zenodo.4725993, 2021.

Jin, F.-F.: An Equatorial Ocean Recharge Paradigm for ENSO. Part I: Conceptual Model, J. Atmos. Sci., $\quad 54, \quad 811-829, \quad$ https://doi.org/10.1175/15200469(1997)054<0811:AEORPF>2.0.CO;2, 1997.

Johnson, G. C., Sloyan, B. M., Kessler, W. S., and McTaggart, K. E.: Direct Measurements of Upper Ocean Currents and Water Properties across the Tropical Pacific during the 1990s,
Prog. Oceanogr., 52, 31-61, https://doi.org/10.1016/S00796611(02)00021-6, 2002.

Johnson, M. A. and O'Brien, J. J.: The Role of Coastal Kelvin Waves on the Northeast Pacific Ocean, J. Marine Syst., 1, 29 38, https://doi.org/10.1016/0924-7963(90)90085-O, 1990.

Knauss, J. A. and Garfield, N.: Introduction to Physical Oceanography, 3rd Edn., Waveland Press, 2016.

Large, W. G. and Yeager, S. G.: The Global Climatology of an Interannually Varying Air-Sea Flux Data Set, Clim. Dynam., 33, 341-364, https://doi.org/10.1007/s00382-008-0441-3, 2009.

Lee, T., Fukumori, I., and Tang, B.: Temperature Advection: Internal versus External Processes, J. Phys. Oceanogr., 34, 1936-1944, https://doi.org/10.1175/15200485(2004)034<1936:TAIVEP>2.0.CO;2, 2004.

McGregor, S., Gupta, A. S., and England, M. H.: Constraining Wind Stress Products with Sea Surface Height Observations and Implications for Pacific Ocean Sea Level Trend Attribution, J. Climate, 25, 8164-8176, https://doi.org/10.1175/JCLI-D-1200105.1, 2012

McPhaden, M. J., Busalacchi, A. J., and Picaut, J.: Observations and Wind-Forced Model Simulations of the Mean Seasonal Cycle in Tropical Pacific Sea Surface Topography, J. Geophys. Res.-Oceans, 93, 8131-8146, https://doi.org/10.1029/JC093iC07p08131, 1988.

Merrifield, M. A.: A Shift in Western Tropical Pacific Sea Level Trends during the 1990s, J. Climate, 24, 4126-4138, https://doi.org/10.1175/2011JCLI3932.1, 2011.

Meyers, G.: On the Annual Rossby Wave in the Tropical North Pacific Ocean, J. Phys Oceanogr., 9, 663-674, https://doi.org/10.1175/15200485(1979)009<0663:OTARWI>2.0.CO;2, 1979.

Peyser, C. E., Yin, J., Landerer, F. W., and Cole, J. E.: Pacific Sea Level Rise Patterns and Global Surface Temperature Variability: pacific sea level and global temperature, Geophys. Res. Lett., 43 , 8662-8669, https://doi.org/10.1002/2016GL069401, 2016.

Picaut, J., Masia, F., and du Penhoat, Y.: An AdvectiveReflective Conceptual Model for the Oscillatory Nature of the ENSO, Science, 277, 663-666, https://doi.org/10.1126/science.277.5326.663, 1997.

Pujol, M.-I. and Mertz, F.: Sea Level TAC DUACS Products, available at: https://resources.marine.copernicus.eu/, last access: 1 July 2019.

Ray, S., Wittenberg, A. T., Griffies, S. M., and Zeng, F.: Understanding the Equatorial Pacific Cold Tongue Time-Mean Heat Budget. Part I: Diagnostic Framework, J. Climate, 31, 9965-9985, https://doi.org/10.1175/JCLI-D-18-0152.1, 2018.

Roquet, F., Madec, G., McDougall, T. J., and Barker, P. M.: Accurate Polynomial Expressions for the Density and Specific Volume of Seawater Using the TEOS-10 Standard, Ocean Model., 90, 29-43, https://doi.org/10.1016/j.ocemod.2015.04.002, 2015.

Taboada, F. G., Stock, C. A., Griffies, S. M., Dunne, J., John, J. G., Small, R. J., and Tsujino, H.: Surface winds from atmospheric reanalysis lead to contrasting oceanic forcing and coastal upwelling patterns, Ocean Model., 133, 79-111, https://doi.org/10.1016/j.ocemod.2018.11.003, 2018.

Tokinaga, H. and Xie, S.-P.: Wave- and Anemometer-Based Sea Surface Wind (WASWind) for Climate Change Analysis, J. Climate, 24, 267-285, https://doi.org/10.1175/2010JCLI3789.1, 2011. 
Trenberth, K. E.: Evolution of El Niño-Southern Oscillation and Global Atmospheric Surface Temperatures, J. Geophys. Res., 107, AAC 5-1-AAC 5-17, https://doi.org/10.1029/2000JD000298, 2002.

Tseng, Y.-h., Lin, H., Chen, H.-C., Thompson, K., Bentsen, M., Böning, C. W., Bozec, A., Cassou, C., Chassignet, E., Chow, C. H., Danabasoglu, G., Danilov, S., Farneti, R., Fogli, P. G., Fujii, Y., Griffies, S. M., Ilicak, M., Jung, T., Masina, S., Navarra, A., Patara, L., Samuels, B. L., Scheinert, M., Sidorenko, D., Sui, C.-H., Tsujino, H., Valcke, S., Voldoire, A., Wang, Q., and Yeager, S. G.: North and Equatorial Pacific Ocean Circulation in the CORE-II Hindcast Simulations, Ocean Model., 104, 143-170, https://doi.org/10.1016/j.ocemod.2016.06.003, 2016.

Tsujino, H., Urakawa, S., Nakano, H., Small, R. J., Kim, W. M., Yeager, S. G., Danabasoglu, G., Suzuki, T., Bamber, J. L., Bentsen, M., Böning, C. W., Bozec, A., Chassignet, E. P., Curchitser, E., Boeira Dias, F., Durack, P. J., Griffies, S. M., Harada, Y., Ilicak, M., Josey, S. A., Kobayashi, C., Kobayashi, S., Komuro, Y., Large, W. G., Le Sommer, J., Marsland, S. J., Masina, S., Scheinert, M., Tomita, H., Valdivieso, M., and Yamazaki, D.: JRA-55 Based Surface Dataset for Driving Ocean-Sea-Ice Models (JRA55-Do), Ocean Model., 130, 79139, https://doi.org/10.1016/j.ocemod.2018.07.002, 2018.

Tsujino, H., Urakawa, L. S., Griffies, S. M., Danabasoglu, G., Adcroft, A. J., Amaral, A. E., Arsouze, T., Bentsen, M., Bernardello, R., Böning, C. W., Bozec, A., Chassignet, E. P., Danilov, S., Dussin, R., Exarchou, E., Fogli, P. G., Fox-Kemper, B., Guo, C., Ilicak, M., Iovino, D., Kim, W. M., Koldunov, N., Lapin, V., Li, Y., Lin, P., Lindsay, K., Liu, H., Long, M. C., Komuro, Y., Marsland, S. J., Masina, S., Nummelin, A., Rieck, J. K., Ruprich-Robert, Y., Scheinert, M., Sicardi, V., Sidorenko, D., Suzuki, T., Tatebe, H., Wang, Q., Yeager, S. G., and Yu, Z.: Evaluation of global ocean-sea-ice model simulations based on the experimental protocols of the Ocean Model Intercomparison Project phase 2 (OMIP-2), Geosci. Model Dev., 13, 3643-3708, https://doi.org/10.5194/gmd-13-3643-2020, 2020.
Vinogradov, S. V., Ponte, R. M., Heimbach, P., and Wunsch, C.: The Mean Seasonal Cycle in Sea Level Estimated from a Data-Constrained General Circulation Model, J. Geophys. Res.Oceans, 113, C03032, https://doi.org/10.1029/2007JC004496, 2008.

Weisberg, R. H. and Wang, C.: A Western Pacific Oscillator Paradigm for the El Niño-Southern Oscillation, Geophys. Res. Lett., 24, 779-782, https://doi.org/10.1029/97GL00689, 1997.

Wyrtki, K.: Sea Level and the Seasonal Fluctuations of the Equatorial Currents in the Western Pacific Ocean, J. Phys. Oceanogr., 4, 91-103, https://doi.org/10.1175/15200485(1974)004<0091:SLATSF>2.0.CO;2, 1974.

Yin, J., Griffies, S. M., and Stouffer, R.: Spatial variability of sealevel rise in 21 st century projections, J. Climate, 23, 4585-4607, https://doi.org/10.1175/2010JCLI3533.1, 2010.

Zebiak, S. E. and Cane, M. A.: A Model El Niño Southern Oscillation, Mon. Weather Rev., 115, 2262-2278, https://doi.org/10.1175/15200493(1987)115<2262:AMENO>2.0.CO;2, 1987.

Zhang, X. and Church, J. A.: Sea Level Trends, Interannual and Decadal Variability in the Pacific Ocean, Geophys. Res. Lett., 39, L21701, https://doi.org/10.1029/2012GL053240, 2012.

Zhang, Z., Xue, H., Chai, F., and Chao, Y.: Variability of the Pacific North Equatorial Current from 1993 to 2012 Based on a $1 / 8^{\circ}$ Pacific Model Simulation, J. Geophys. Res.-Oceans, 122, 23822400, https://doi.org/10.1002/2016JC012143, 2017. 